UNIVERSIDADE DE SÃO PAULO

FACULDADE DE FILOSOFIA, CIÊNCIAS E LETRAS DE RIBEIRÃO PRETO DEPARTAMENTO DE PSICOLOGIA E EDUCAÇÃO PROGRAMA DE PÓS-GRADUAÇÃO EM PSICOBIOLOGIA

GISELE STRAATMANN

Estresse, estratégias de enfrentamento e a percepção da imagem corporal em adolescentes: relações com o estado nutricional

Ribeirão Preto

2010 


\section{GISELE STRAATMANN}

\section{Estresse, estratégias de enfrentamento e a percepção da imagem corporal em adolescentes: relações com o estado nutricional}

Tese apresentada à Faculdade de Filosofia, Ciências e Letras de Ribeirão Preto, como parte das exigências para obtenção do título de Doutor em Ciências, área de concentração Psicobiologia.

Orientador: Prof. Dr. Sebastião de Sousa Almeida

Ribeirão Preto 
AUTORIZO A REPRODUÇÃO E DIVULGAÇÃO TOTAL OU PARCIAL DESTE TRABALHO, POR QUALQUER MEIO CONVENCIONAL OU ELETRÔNICO, PARA FINS DE ESTUDO E PESQUISA, DESDE QUE CITADA A FONTE.

\section{FICHA CATALOGRÁFICA}

Straatmann, Gisele

Estresse, estratégias de enfrentamento e a percepção da imagem corporal em adolescentes: relações com o estado nutricional. Ribeirão Preto, 2010.

83 p. : il. ; $30 \mathrm{~cm}$

Tese de Doutorado, apresentada à Faculdade de Filosofia, Ciências e Letras de Ribeirão Preto/USP. Área de concentração: Psicobiologia.

Orientador: Almeida, Sebastião de Sousa.

1. Estresse. 2. Estratégias de enfrentamento. 3. Imagem corporal. 4. Estado nutricional. 5. Adolescência 


\section{FOLHA DE APROVAÇÃO}

Gisele Straatmann

"Estresse, estratégias de enfrentamento e a percepção da imagem corporal em adolescentes: relações com o estado nutricional"

Tese apresentada à Faculdade de Filosofia, Ciências e Letras de Ribeirão Preto da USP, como parte das exigências para a obtenção do título de Doutor em Ciências. Área de Concentração: Psicobiologia.

Aprovada em:

\section{Banca Examinadora}

$\operatorname{Prof}(\mathrm{a}) . \operatorname{Dr}(\mathrm{a})$.

Instituição:

Assinatura:

$\operatorname{Prof}(\mathrm{a}) . \operatorname{Dr}(\mathrm{a})$

Instituição:

Assinatura:

$\operatorname{Prof}(\mathrm{a}) . \operatorname{Dr}(\mathrm{a})$.

Instituição:

Assinatura:

$\operatorname{Prof}(\mathrm{a}) . \operatorname{Dr}(\mathrm{a})$.

Instituição:

Assinatura:

Prof (a). Dr (a).

Instituição:

Assinatura: 
Ao Daniel, por seu amor, paciência e por estar ao meu lado em todos os momentos; aos meus pais e minha família, por acreditarem em mim e sempre me apoiarem. 
AGRADECIMENTOS 


\section{AGRADECIMENTOS}

Ao Prof. Dr. Sebastião Sousa Almeida pelo carinho, compreensão, contribuição no meu processo de aprendizado e ajuda constante durante a execução deste trabalho.

À banca de qualificação: Prof ${ }^{\natural}$. Dra. Sandra Leal Calais, Prof ${ }^{\natural}$. Dra. Carmem Beatriz Neufeld e Prof ${ }^{a}$. Dra. Maria Aparecida Conti que, muito respeitosamente e a partir da peculiaridade de seus conhecimentos, realizaram leituras atenciosas, colaboraram para reflexão e contribuíram para o enriquecimento do trabalho.

Aos meus pais pelo amor e apoio incondicional e por me oferecerem as condições necessárias para minha formação pessoal e profissional.

Ao meu marido Daniel, meu eterno amor, pela presença carinhosa e dedicada.

À minha família (meu maninho Jefe, Carol, Ana Beatriz, Luís Fernando, Sônia, vó Gilda) pelo carinho e preocupação.

À minha família do sul sempre presente em minha vida apesar da distância.

Aos meus amigos do Laboratório de Nutrição e Comportamento (Fer, Paula, Marisa, Lucas, Beto, Edson, Nati, Mari, Renata, Diana, Idalina, Fabiana, Luciana, Camila) pelo apoio, amizade e companheirismo durante todos esses anos.

Aos amigos fiéis que sempre vibraram e estiveram comigo.

À direção e aos funcionários das escolas públicas pelo consentimento e ajuda na realização deste trabalho.

A todos os adolescentes e familiares pela imprescindível colaboração nesta pesquisa.

À Fundação de Amparo à Pesquisa do Estado de São Paulo - FAPESP (Processo ${ }^{\circ}$ 2007/08584-0) pelo financiamento deste trabalho. 


\section{RESUMO}

\section{STRAATMANN, G. Estresse, estratégias de enfrentamento e a percepção da imagem}

corporal em adolescentes: relações com o estado nutricional. Tese (Doutorado) Faculdade de Filosofia, Ciências e Letras de Ribeirão Preto, Universidade de São Paulo, Ribeirão Preto, 2010.

O estresse, as estratégias de enfrentamento utilizadas em uma situação envolvendo desconforto com o corpo, a imagem corporal e o estado nutricional em adolescentes foram investigados no presente estudo. A amostra foi composta por 166 meninas e 47 meninos, com idade entre 15 a 18 anos, matriculados em escolas públicas do ensino médio do município de Ribeirão Preto-SP. Os principais instrumentos utilizados foram o Inventário de Sintomas de Stress para Adultos de LIPP, o Inventário de Estratégias de Coping de Folkman e Lazarus e a Escala de Figuras de Silhuetas de Kakeshita, Silva, Zanatta e Almeida. Os padrões utilizados para a classificação do estado nutricional foram os da OMS. Mais da metade dos adolescentes apresentaram sintomas de estresse e estes utilizaram mais significativamente todas as estratégias de enfrentamento em uma situação de desconforto com o corpo do que aqueles sem sintomas de estresse. De maneira geral, as estratégias de enfrentamento mais utilizadas foram aquelas centradas na emoção. $O$ sexo feminino utilizou mais as estratégias de autocontrole, fuga e esquiva e reavaliação positiva, enquanto que o sexo masculino utilizou mais a estratégia de fuga e esquiva. Os adolescentes insatisfeitos negativamente apresentaram uma maior probabilidade de utilizarem a estratégia de aceitação de responsabilidade. Tanto os meninos quanto as meninas estavam insatisfeitos com seu tamanho corporal e ambos o superestimaram. Comparando ambos os sexos, as meninas mostraram uma maior inacurácia na percepção corporal do que os meninos. A correlação entre insatisfação corporal e inacurácia da percepção corporal foi negativa e moderada. A maioria dos adolescentes estava no estado nutricional de eutrofia. Os resultados do presente estudo podem ter implicações importantes em relação à prevenção do desenvolvimento de uma imagem corporal negativa.

Palavras-chave: Estresse. Estratégias de enfrentamento. Imagem corporal. Estado nutricional. Adolescência. 


\begin{abstract}
STRAATMANN, G. Stress, coping strategies and body image perceptions in adolescents: relation with nutritional status. Thesis (Doctorate) - Faculdade de Filosofia, Ciências e Letras de Ribeirão Preto, Universidade de São Paulo, Ribeirão Preto, 2010.

This research aimed to investigate stress, body image coping strategies used by adolescents, body image and nutritional status. A sample of 166 girls and 47 boys, aged 15 to 18 years, was recruited from public high schools in Ribeirão Preto, state of São Paulo, Brazil. The main outcome measures used were Lipp Stress Symptoms Inventory, The Ways of Coping Questionnaire and Kakeshita, Silva, Zanatta and Almeida Figure Rating Scale. The WHO standards were used to evaluate the nutritional status. More than half of adolescents showed symptoms of stress and used significantly more all coping strategies in a situation of body discomfort compared with those without symptoms of stress. In general, the predominant body image coping strategies used by adolescents were emotion-focused coping. Girls used more strategies of self-control, escape-avoidance and positive reappraisal, whereas males used more escape-avoidance strategy. Negatively body dissatisfied adolescents had a greater likelihood of using accepting responsibility coping. Both genders were negatively body dissatisfied and showed positively body size estimation inaccuracy. Comparing both sexes, girls showed greater inaccuracy in body estimation than boys. The correlation between body dissatisfaction and body estimation inaccuracy was negative and moderate. Most of the the population studied was eutrophic. The results of this study may have important implications for prevention and development of a negative body image.
\end{abstract}

Keywords: Stress. Coping. Body image. Nutritional status. Adolescence. 


\section{LISTA DE FIGURAS}

Figura 1. Escala de figuras de silhuetas para mulheres e homens

Figura 2. Box-Plot dos escores de insatisfação e inacurácia da percepção corporal $\left(\mathrm{kg} / \mathrm{m}^{2}\right)$ nos adolescentes de acordo com o sexo. Ribeirão Preto, SP, 20082009 .

Figura 3. Box-Plot dos escores de insatisfação e inacurácia da percepção corporal $\left(\mathrm{kg} / \mathrm{m}^{2}\right)$ nos adolescentes de acordo com o estado nutricional. Ribeirão Preto, SP, 2008-2009

Figura 4. Distribuição dos adolescentes com insatisfação, satisfação corporal e inacurácia da percepção corporal de acordo o sexo. Ribeirão Preto, SP, 2008-2009 


\section{LISTA DE TABELAS}

Tabela 1. Características socioeconômicas e nutricionais, escores de estresse e imagem corporal dos adolescentes por sexo e estado nutricional. Ribeirão Preto, SP, 2008-2009

Tabela 2. Média dos fatores de coping por sexo, estresse, estado nutricional e imagem corporal. Ribeirão Preto, SP, 2008-2009

Tabela 3. Correlação múltipla dos fatores de coping. Ribeirão Preto, SP, 2008- 2009 46 


\section{SUMÁRIO}

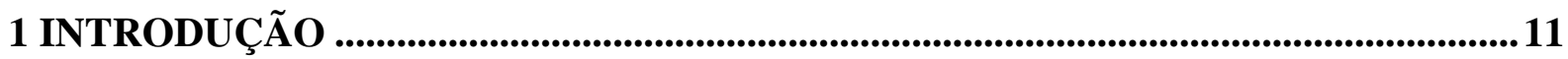

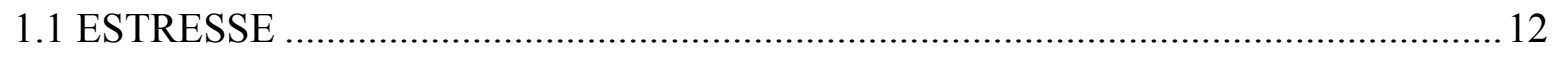

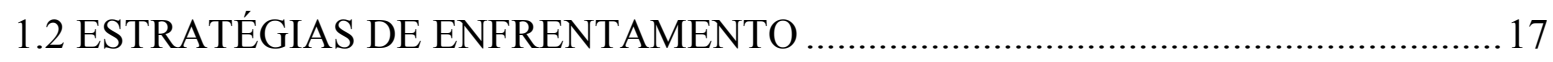

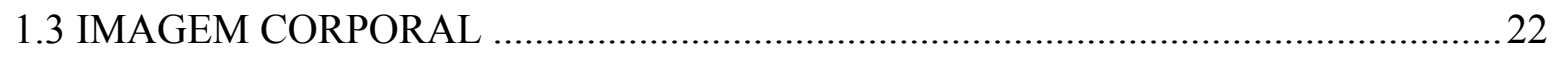

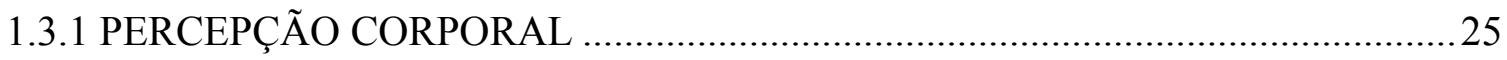

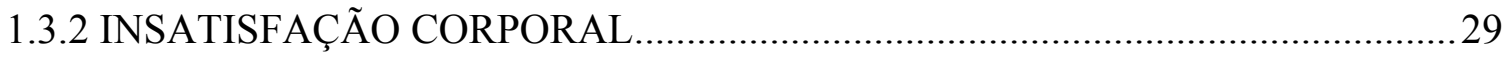

1.3.3 FATORES QUE INFLUENCIAM A IMAGEM CORPORAL ………....................32

1.3.4 CONSEQÜENCIAS DA IMAGEM CORPORAL PARA A SAÚDE.......................33

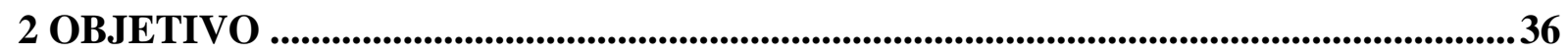

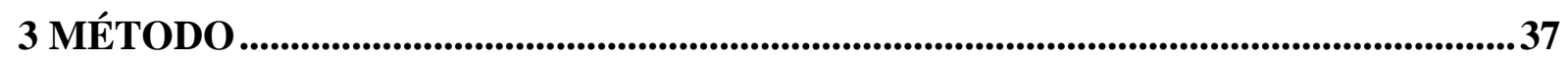

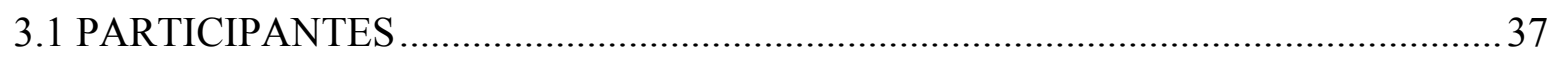

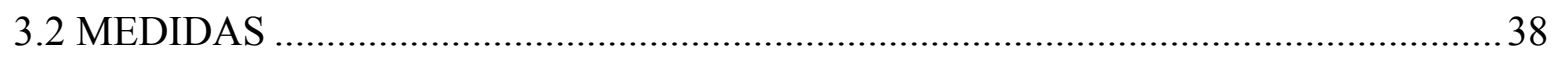

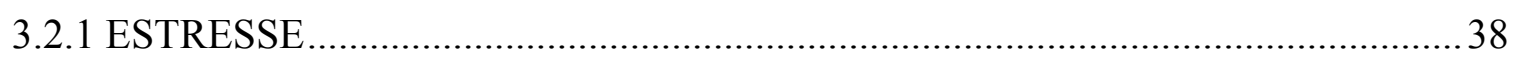

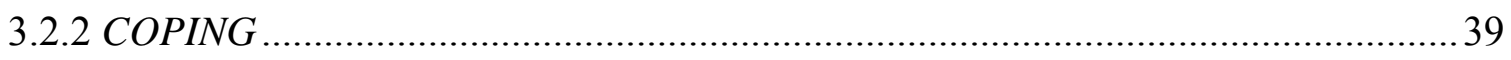

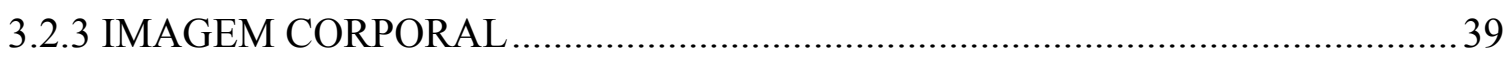

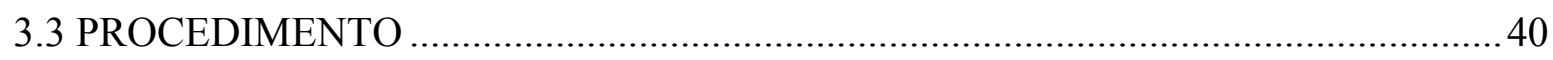

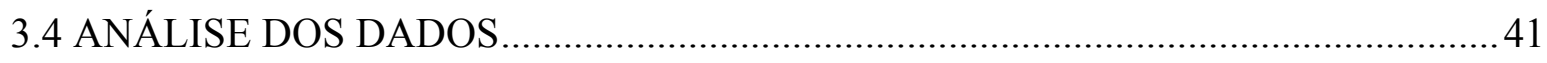

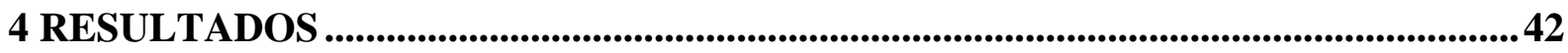

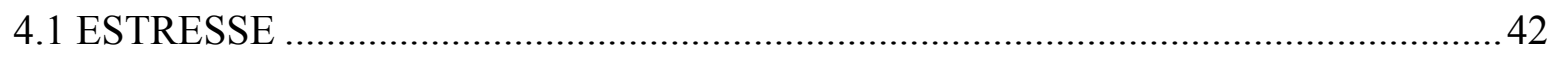

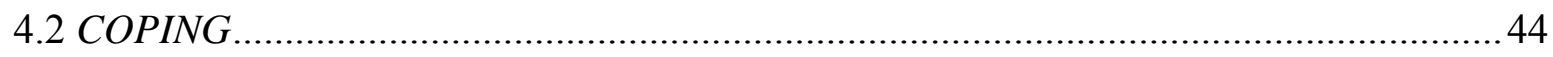

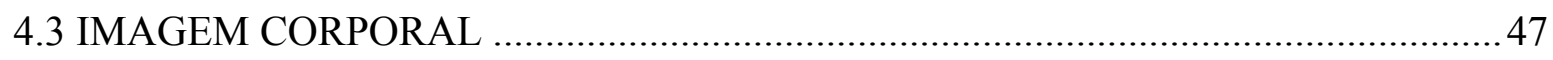

4.4 ASSOCIAÇÕES ENTRE AS VARIÁVEIS DO ESTUDO …………………................49

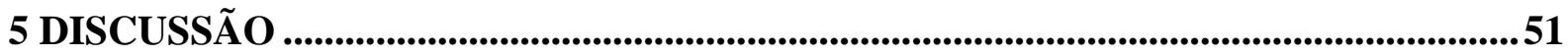

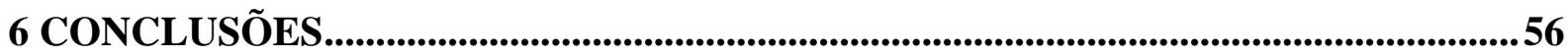

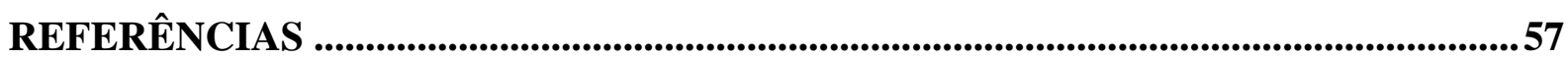

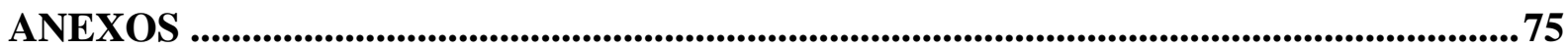




\section{INTRODUÇÃO}

O estresse é um traço predominante do desenvolvimento humano ao longo da vida, principalmente durante a adolescência. Segundo Gutman e Eccles (2007), a adolescência é um período transacional da infância para a idade adulta único em sua multiplicidade de mudanças simultâneas que ocorrem em vários contextos. De acordo com Breinbauer e Maddaleno (2008), os adolescentes precisam se adaptar a uma série de mudanças normativas e a uma maior expectativa de agir de uma maneira mais madura. Além disso, desenvolvem mais autocríticas e dedicam mais tempo julgando a si mesmos e avaliando como os outros os vêem. Esse período também é marcado por várias experiências relacionadas a mudanças no corpo, mudanças sociais e a uma autonomia comportamental cada vez maior.

Segundo a Organização Mundial da Saúde - OMS (1965), a adolescência é definida como um período biopsicossocial que compreende a segunda década da vida (10 aos 19 anos). Para o Estatuto da Criança e do Adolescente - ECA, o período vai dos 12 aos 18 anos (BRASIL, 2008). Em geral, a adolescência começa com o desencadeamento da puberdade e termina com a aceitação de responsabilidades adultas (NEWCOMBE, 1999, p. 404). SchoenFerreira, Aznar-Farias e Silvares (2010) colocam que, a adolescência, cujo início coincide com a puberdade, é influenciada pelas manifestações desta e enfatizam a distinção entre puberdade e adolescência. A puberdade refere-se aos fenômenos fisiológicos, que compreendem as mudanças corporais e hormonais, enquanto a adolescência diz respeito aos componentes psicossociais desse mesmo processo. E esses componentes psicossociais são influenciados pela inserção histórica e cultural e assim, variadas formas de viver a adolescência são determinadas de acordo com o gênero, o grupo social e a geração (MARTINS; TRINDADE; ALMEIDA, 2003).

No século XX a cultura ocidental valorizou a adequação a um padrão ideal corporal para o sexo feminino e masculino, o qual ainda é predominante nos dias atuais. Para o sexo feminino, o ideal corporal de atratividade, transmitido e reforçado por várias influências sociais, corresponde a um padrão de magreza (DITTMAR, 2009) enquanto que para o sexo masculino, o padrão valorizado corresponde a um tipo físico musculoso e magro (POPE et al., 1999). A internalização desses padrões irreais corporais retratados e a busca por uma adequação a esses padrões são considerados fatores de risco no desenvolvimento de preocupações corporais e desordens alimentares, principalmente para os adolescentes 
(HARRISON, 2006; HOMAN, 2010; KNAUSS; PAXTON; ALSAKER, 2007; LIN; REID, 2009).

Considerando que a todo instante o corpo físico do adolescente se modifica e essas intensas transformações muitas vezes não correspondem a um ideal corporal valorizado pela sociedade, um grande desafio na adolescência é ficar confortável com um corpo que está mudando rapidamente em um curto espaço de tempo (BOGT et al., 2006). Para Garcia (2010) as maneiras como os adolescentes enfrentam ou respondem aos estressores influenciam o bem-estar deles.

Nesse sentido é importante a investigação do nível de estresse nessa fase do desenvolvimento, assim como a identificação das estratégias de enfrentamento utilizadas pelos adolescentes para enfrentarem situações específicas de incômodo com o próprio corpo e as possíveis relações com a imagem corporal. Segundo Mulye et al. (2009), a adolescência e a juventude são períodos únicos na vida nos quais se apresentam oportunidades de mudanças para melhorar a saúde.

\subsection{ESTRESSE}

A adaptação sob condições de estresse é uma prioridade para todos os organismos, visto que é uma resposta fisiológica necessária para a sobrevivência das espécies. A resposta fisiológica ao estresse envolve uma série eficiente e altamente conservada de sistemas interligados com o objetivo de manterem a integridade fisiológica mesmo nas circunstâncias mais exigentes (ULRICH-LAI; HERMAN, 2009).

Hans Selye, em 1956, foi um dos primeiros cientistas a explicar o processo de estresse, relacionando-o com a Síndrome de Adaptação Geral. Este autor definiu estresse como uma reação inespecífica do organismo a qualquer exigência. Ao interpretar as repercussões fisiológicas do estresse, o autor descreveu a Síndrome de Adaptação Geral, que foi caracterizada como uma reação defensiva fisiológica do organismo em resposta a qualquer estímulo aversivo. Essa síndrome inclui três fases: reação de alarme, de resistência e de exaustão (SELYE, 1965).

A primeira fase, reação de alarme, consiste em reconhecer o estressor e preparar-se para a ação. Alguns sintomas que caracterizam essa fase são taquicardia, sudorese, cefaléia, alterações da pressão arterial, irritabilidade, fadiga, tensão muscular e(,) sensação de 
esgotamento, entre outros. A segunda fase ocorre quando há persistência do estressor e é compatível a adaptação. A ansiedade, o isolamento social, a impotência sexual, a falta ou excesso de apetite e medo são alguns dos sintomas que caracterizam a fase de resistência. Por fim, quando o estressor permanece e a defesa não funciona, o organismo tende a mover-se para a terceira fase - a exaustão - onde os mecanismos adaptativos entram em colapso, levando ao aparecimento de doenças crônicas e podendo culminar com a morte. É importante enfatizar que essa teoria ficou conhecida como a Teoria do Estresse Biológico (LIPP, 2000).

A teoria desenvolvida por Hans Selye propôs um modelo trifásico do estresse (fases de Alerta, Resistência e Exaustão), embasando estudos para os efeitos da tensão excessiva no corpo e na mente. No estudo desse modelo trifásico, Lipp (2000) identificou estatisticamente uma quarta fase, à qual deu o nome de Quase-Exaustão. Esta fase se encontra entre as fases de resistência e exaustão e se caracteriza por um enfraquecimento da pessoa, que passa a não mais conseguir se adaptar ou resistir ao estressor. As doenças começam a surgir, porém, não são tão graves como em exaustão (LIPP, 2003, p.19). Deste modo, Lipp sugere um modelo quadrifásico como um desenvolvimento do modelo trifásico de Selye.

Outras teorias psicológicas sobre o fenômeno de estresse têm incorporado outras variáveis aos modelos explicativos, como a avaliação cognitiva e as respostas de enfrentamento. No modelo de estresse proposto por Folkman e Lazarus (1980), o estresse é definido como uma transação entre a pessoa e o meio, caracterizada por desequilíbrio entre os recursos do indivíduo e a demanda percebida. As condições dinâmicas presentes no meio podem ser percebidas como oportunidades, limites ou demandas. Perceber uma condição como estressante vai depender de valores e necessidades das diferentes pessoas, que podem variar quanto às exigências de reconhecimento e aceitação, segurança, necessidades físicas, estimulação, grau de certeza e previsibilidade. Ainda, apoiando-se nesta concepção, pode-se falar em estresse positivo, quando o desequilíbrio é percebido como oportunidade. Quando é percebido como uma exigência ou limitação, fala-se em estresse negativo. O tipo de estresse (de demanda, oportunidade ou limitação) está associado a diferentes sintomas físicos, psicológicos ou comportamentais (SEIDL; TRÓCCOLI; ZANNON, 2001).

Portanto, muitos fatores influenciam o padrão e a magnitude da resposta ao estresse, tais como a duração da exposição ao estresse (agudo versus crônico), o tipo de estresse (físico versus psicológico), o contexto do estresse (por exemplo, o período do dia), o desenvolvimento do indivíduo (infância, adolescência, adulto ou idoso), o sexo e a genética (JOËLS; BARAM, 2009). 
Segundo Arnett (1999), a probabilidade de desenvolver o estresse é maior na adolescência do que em qualquer outra faixa etária, dependendo da cultura e de diferenças individuais existentes. A maioria das pesquisas sobre estresse em adolescentes enfatiza o estudo de eventos traumáticos e estressores crônicos no desenvolvimento, caracterizados por perdas, ameaças e doenças, e poucos estudos investigam os estressores do dia a dia que frequentemente ocorrem durante a adolescência (SEIFFGE-KRENKE; AUNOLA; NURMI, 2009).

A maioria dos adolescentes é confrontada diariamente com situações estressantes. É importante notar que os eventos diários estressantes nomeados pelos adolescentes geralmente estão relacionados a relações interpessoais (EBATA; MOOS, 1994; SEIFFGE-KRENKE, 2006) e incluem conflitos com os pais (SEIFFGE-KRENKE et al., 2001; THORNTON; ORBUCH; AXINN, 1995), com amigos (BOWKER et al., 2000) e namorados (NIEDER; SEIFFGE-KRENKE, 2001). Outros estressores estão relacionados a preocupações com a própria identidade tais como insatisfação com o próprio corpo, aparência, traços e características (SEIFFGE-KRENKE; AUNOLA; NURMI, 2009).

Calais, Andrade e Lipp (2003) investigaram os sintomas de estresse em adultos jovens brasileiros de 15 a 28 anos e notaram que $65,60 \%$ dos participantes apresentaram estresse de acordo com o Inventário de Sintomas de Stress de Lipp (ISSL). Uma correlação significativa entre sexo e nível de estresse foi encontrada, indicando um maior nível de estresse no sexo feminino, sendo que 79,3\% delas possuíam sintomas significativos de estresse e encontravamse, em sua maioria, na fase de resistência $(98,31 \%)$.

Em outro estudo realizado com o mesmo instrumento (ISSL), Pires et al. (2004) analisaram a vulnerabilidade ao estresse em adolescentes do ensino médio da rede pública e particular de Florianópolis. Os resultados mostraram que 43,1\% apresentavam sintomas de estresse, sendo que $95 \%$ deles estavam na fase de resistência e apresentavam predominância de sintomas psicológicos $(76,4 \%)$. A proporção de adolescentes do gênero feminino com estresse foi quase o dobro $(54,4 \%)$ em comparação com o gênero masculino $(28,8 \%)$.

Nota-se nesses dois estudos uma diferença de gênero em relação ao estresse. Segundo Barnett, Biener e Baruch (1987) o gênero afeta o processo de estresse tanto na determinação se uma situação será percebida como estressante assim como influenciando as respostas de enfrentamento e as implicações na saúde das reações de estresse. Na literatura vários autores mostram que o sexo feminino se encontra com mais frequência em situações de estresse do que o sexo masculino (e.g., ALMEIDA; KESSLER, 1998; McDONOUGH; WALTERS, 2001). Outros autores sugerem que é possível que as mulheres avaliem situações de risco 
como mais estressantes do que os homens (MILLER; KIRSCH, 1987; PTACEK; SMITH; ZANAS, 1992).

Davis, Burleson e Kruszewski (2011) também ressaltam que o gênero pode estar envolvido na experiência do estresse, determinando a exposição aos eventos e a avaliação desses eventos como estressante, assim como influenciando respostas fisiológicas e esforços de enfrentamento. $O$ gênero pode também modelar a relação entre o estresse e as conseqüências para a saúde visto que, mesmo quando o estresse é comparável, um gênero pode ser mais vulnerável à consequências negativas do que outro.

Por que a diferença de sexo pode influenciar na experiência do estresse? Alguns teóricos oferecem explicações para as diferenças entre o sexo feminino e masculino que enfatizam fatores baseados na biologia (HINOJOSA-LABORDE et al., 1999; TAYLOR et al., 2000), mas observa-se que o gênero também é uma categoria social que influencia profundamente em como os outros nos observam e como nós nos vemos (DAVIS; BURLESON; KRUSZEWSKI, 2011). Cada sociedade impõe um sistema de regras sociais e costumes referentes ao que o sexo feminino e masculino têm que supostamente ser e fazer, e as pessoas embutem esses papéis sociais que por um lado modela suas próprias habilidades e crenças (DAVIS; BURLESON; KRUSZEWSKI, 2011). Portanto, os fatores psicossociais influenciam as diferenças de gênero encontrada no estresse por meio do destaque dos papéis sociais pela cultura assim como na socialização desses papéis na interação da pessoa com seu ambiente.

É conhecido que o estresse pode levar a hábitos e comportamentos prejudiciais à saúde. Reações comportamentais ao estresse incluem ações para remover ou fugir da fonte de estresse ou reações dirigidas para amenizar as consequências emocionais negativas (BENETT; COOPER, 1999). Deste modo, o estresse pode ser um fator que precipita hábitos e comportamentos prejudiciais à saúde assim como pode desempenhar um papel na progressão e manutenção deles.

Muitas pesquisas mostram a relação entre o estresse e uma série de fatores relacionados à saúde. O estudo de Johnson e Wardle (2005), por exemplo, avaliou o quanto o estresse, a alimentação emocional, a compulsão alimentar, atitudes anormais para alimentação e peso, baixa autoestima e depressão estavam associados com dieta restritiva ou insatisfação corporal. Nas análises que incluíram tanto a dieta restritiva quanto a insatisfação corporal como preditores independentes, a insatisfação corporal permaneceu um preditor significativo para o estresse, depressão e baixa autoestima. 
Um estudo recente de Murray, Byrne e Rieger (2010) explorou a relação entre estresse e imagem corporal na adolescência. Além disso, avaliaram a autoestima e os sintomas depressivos como medidas adicionais para a compreensão da ligação do estresse com a imagem corporal. Os instrumentos utilizados para avaliar o estresse e a imagem corporal foram o Adolescent Stress Questionnaire (BYRNE; DAVENPORT; MAZANOV, 2007) e Self-Image Questionnaire for Young Adolescents (PETERSEN et al., 1984), respectivamente. Os resultados indicaram que o estresse tem uma proporção considerável na variação da imagem corporal. A pressão dos pares e a escola foram estressores significativos correlacionados à imagem corporal em ambos os sexos. Além disso, altos níveis de estresse reportados estavam associados com uma imagem corporal disfuncional, baixa autoestima e muitos sintomas depressivos. Portanto, a autoestima estava relacionada positivamente e os sintomas depressivos negativamente à imagem corporal.

Muitos estudos também mostram uma associação entre estresse e alimentação emocional (NGUYEN-RODRIGUEZ et al., 2008). Em um estudo de revisão sobre o estresse induzindo a alimentação, Greeno e Wing (1994) concluíram que o estresse geralmente leva a um excesso alimentar. Michaud et al. (1990) descobriram que o estresse aumenta a ingestão de alimentos em uma amostra de estudantes franceses e concluíram que esse comportamento poderia levar a um aumento de peso com o tempo. Outro estudo, com crianças de 8 a 11 anos, mostrou que os indivíduos que controlavam mais a ingestão energética eram mais propensos a comerem frente ao estresse, o que poderia levar ao ganho de peso quando na ausência desse controle (ROEMICH; WRIGHT; EPSTEIN, 2002). Cartwright et al. (2003) examinou estudantes da sétima série em Londres e constatou que o alto grau de estresse percebido foi relacionado com o alto consumo de gorduras e de grandes quantidades de refeições não saudáveis. Por fim, Jaarsveld et al.(2009) investigaram associações entre o estresse percebido e mudanças no índice de massa corporal (IMC) em adolescentes, durante cinco anos. O IMC foi significativamente maior nos grupos de estresse moderado e alto do que no grupo com baixo estresse nos cinco anos do estudo.

Nota-se, portanto, que a resposta de estresse, que pode ter fornecido as ferramentas necessárias para nossos ancestrais nos tempos da pré-história para a sobrevivência na presença de predadores, hoje pode ter conseqüências negativas para o desenvolvimento do cérebro e para a saúde mental (LUPIEN et al., 2009). Portanto, aprender estratégias de enfrentamento saudáveis durante esse período é crucial visto que é um período crítico no qual comportamentos saudáveis começam a se solidificar e podem seguir na vida adulta (NGUYEN-RODRIGUEZ et al., 2008). 


\subsection{ESTRATÉGIAS DE ENFRENTAMENTO}

Para o domínio das situações de estresse e adaptação a elas, os indivíduos desenvolvem habilidades denominadas coping, também chamada de estratégias ou processos de enfrentamento. O coping é conceitualizado como "tentativas de mudanças comportamentais e cognitivas constantes para lidar com demandas externas e/ou internas específicas que são avaliadas como exigindo ou excedendo os recursos da pessoa" (LAZARUS; FOLKMAN, 1984). Neste modelo teórico as experiências estressantes são interpretadas como interações entre pessoa e ambiente, nas quais o impacto de um estressor é mediado pela avaliação cognitiva que a pessoa faz do estressor e pelos recursos psicológicos, sociais e culturais de que dispõe. Segundo Lazarus e Folkman (1984), a avaliação cognitiva pode ser compreendida com o processo de categorização de uma situação e suas várias faces, com respeito a seu significado para o bem-estar. Os autores descrevem dois processos de avaliação cognitiva do estímulo ou evento estressor: avaliação primária e secundária.

Na avaliação primária podem ser distinguidos três tipos de avaliações: (1) irrelevante, (2) positivo benigno e (3) estressante. Quando uma situação não tem implicação para o bemestar da pessoa, ela entra na categoria de irrelevante. Avaliações positivas benignas ocorrem se a resposta a uma situação é construída como positiva, ou seja, se ela preserva ou melhora o bem estar ou promete fazê-lo. Por fim, avaliações estressantes incluem danos/perdas, ameaças e desafios (LAZARUS; FOLKMAN, 1984).

Já a atividade de avaliação secundária é um recurso crucial para cada situação estressante porque a resposta depende sobre o quê e se alguma coisa pode ser feita, assim como saber o que está em jogo. A avaliação secundária é um complexo processo avaliativo que leva em consideração quais estratégias de enfrentamento estão disponíveis, a probabilidade de que uma dada opção de estratégia será efetiva para a situação, e a probabilidade de que se pode aplicar uma determinada estratégia ou um conjunto de estratégias efetivamente. Ambas avaliações cognitivas (primárias e secundárias) interagem uma com a outra e configuram o grau de estresse assim como a reação emocional (LAZARUS; FOLKMAN, 1984).

Segundo essa teoria, a maior parte das pessoas recorre a cerca de oito estratégias de coping em todos os acontecimentos de estresse (Quadro 1). De acordo com a situação de estresse, a pessoa utiliza diferentes estratégias de coping simultaneamente. 


\begin{tabular}{|l|l|}
\hline Fatores & Descrição \\
\hline $\begin{array}{l}\text { Confronto } \\
\text { Confrontive coping) }\end{array}$ & $\begin{array}{l}\text { Descreve os esforços agressivos de } \\
\text { alteração da situação e sugere um certo } \\
\text { grau de hostilidade e risco. }\end{array}$ \\
\hline $\begin{array}{l}\text { Afastamento } \\
\text { Distancing) }\end{array}$ & $\begin{array}{l}\text { Descreve os esforços cognitivos de } \\
\text { desprendimento e minimização da } \\
\text { situação. }\end{array}$ \\
\hline $\begin{array}{l}\text { Autocontrole } \\
\text { (Self-controlling) }\end{array}$ & $\begin{array}{l}\text { Descreve os esforços de regulação dos } \\
\text { próprios sentimentos e ações. }\end{array}$ \\
\hline $\begin{array}{l}\text { Suporte social } \\
\text { Seeking social support) }\end{array}$ & $\begin{array}{l}\text { Descreve os esforços de procura de } \\
\text { suporte informativo, suporte tangível e } \\
\text { suporte emocional. }\end{array}$ \\
\hline $\begin{array}{l}\text { Aceitação de responsabilidade } \\
\text { Accepting responsability) }\end{array}$ & $\begin{array}{l}\text { Reconhecimento do próprio papel no } \\
\text { problema e concomitante tentativa de } \\
\text { recompor as coisas. }\end{array}$ \\
\hline $\begin{array}{l}\text { Fuga e esquiva } \\
\text { (Escape-avoidance) }\end{array}$ & $\begin{array}{l}\text { Descreve os esforços cognitivos e } \\
\text { comportamentais desejados para fugir ou } \\
\text { evitar o problema. Os itens dessa escala } \\
\text { contrastam com os da escala de } \\
\text { afastamento, que sugerem } \\
\text { desprendimento. }\end{array}$ \\
\hline $\begin{array}{l}\text { Descreve os esforços focados sobre o } \\
\text { problema, deliberados para alterar a } \\
\text { situação, associados a uma abordagem } \\
\text { analítica de solução do problema. }\end{array}$ \\
\hline $\begin{array}{l}\text { Resolução de problemas } \\
\text { (Planful problem solving) }\end{array}$ & $\begin{array}{l}\text { Descreve os esforços de criação de } \\
\text { significados positivos, focando o } \\
\text { crescimento pessoal. Tem também uma } \\
\text { dimensão religiosa. }\end{array}$ \\
\hline
\end{tabular}

Quadro 1 - Descrição dos fatores de coping.

Fonte: Folkman \& Lazarus (1988)

Um importante aspecto da teoria refere-se às funções do coping, que se diferenciam das consequências do coping. A função diz respeito à finalidade de uma estratégia, enquanto que a conseqüência refere-se ao efeito que uma estratégia tem. Uma estratégia pode ter uma dada função - por exemplo, evitação - mas não resultar em evitação. De acordo com Lazarus e Folkman (1984), o coping pode ser agrupado dentro de duas dimensões básicas baseadas em suas funções: coping focado no problema (função de alterar o ambiente da situação, tentativas de lidar com o impacto da situação estressante) e coping focado na emoção (regular os estados emocionais causados pelo estresse). Em geral, as estratégias de coping focado na emoção são mais prováveis de ocorrem quando houve uma avaliação de que nada pode ser feito para modificar as condições ambientais prejudiciais, ameaçadoras ou desafiadoras. As estratégias de coping focado no problema, por outro lado, são mais prováveis quando tais condições são avaliadas como passíveis de mudanças (FOLKMAN; LAZARUS, 1985). 
Uma variedade de estratégias de coping focado na emoção é encontrada na literatura e consiste nos processos cognitivos direcionados para a diminuição do estresse emocional, que incluem estratégias tais como evitação, minimização, afastamento, atenção seletiva, tirar o valor positivo de eventos negativos e comparações positivas. As estratégias de coping focado na emoção são usadas para manter a esperança e o otimismo, para negar o fato e as implicações, se recusar a reconhecer o pior, agir como se o que aconteceu não importasse, e assim por diante (LAZARUS; FOLKMAN, 1984).

Já as estratégias focadas no problema são similares às estratégias usadas para resolução de problemas. Como tais, essas estratégias são frequentemente direcionadas para a definição do problema, para a geração de soluções alternativas, ponderando as alternativas em termos de seus custos e benefícios, e para a escolha e ação entre elas (LAZARUS; FOLKMAN, 1984). A maneira como uma pessoa enfrenta uma situação é determinada em parte por seus recursos, os quais incluem: saúde e disposição; crenças existenciais, tais como Deus ou crenças gerais sobre controle; comprometimentos, os quais têm uma propriedade emocional que pode ajudar a sustentar a estratégia de coping; habilidades de resolução de problemas; habilidades sociais; suporte social; e recursos materiais.

Outro fator muito questionado que pode influenciar a maneira de enfrentamento é a diferença de gênero. Davis, Burleson e Kruszewski (2011) colocam que o homem seria mais inclinado a confrontar o estressor diretamente, consistente com coping focado no problema, enquanto que a mulher estaria mais propensa a tentar regular as emoções eliciadas pelo estressor e procurar por apoio social. E, de fato, muitos estudos mostram que quando os indivíduos são questionados sobre suas respostas usuais frente ao estresse, os resultados são que os homens utilizam mais coping focado no problema e as mulheres na emoção (FOLKMAN; LAZARUS, 1980; PEARLIN; SCHOOLER, 1978).

No entanto, é importante destacar que o coping depende da situação estressante específica, pois a natureza do estressor influencia a seleção das respostas de coping (DAVIS; BURLESON; KRUSZEWSKI, 2011). Portanto, a investigação das estratégias de enfrentamento por gênero tem que envolver um mesmo tipo de estressor para identificação das diferenças. Tamres, Janicki e Helgeson (2002) conduziram uma revisão quantitativa de 50 estudos que avaliavam as resposta de coping de homens e mulheres que passaram por estressores similares: desde doenças crônicas ao humor disfórico, infertilidade e falecimento de uma criança. Em todos estressores as mulheres reportaram o uso de mais estratégias de coping do que os homens, incluindo aquelas categorizadas como focadas no problema ou emoção. As mulheres, portanto, usaram mais estratégias de coping do que os homens, 
incluindo aquelas que podem ser consideras consistentes com o gênero (coping focado na emoção) e inconsistentes (coping focado no problema).

Independente dos papéis de gênero, estudos têm mostrado que as pessoas tendem a empregar ambas as estratégias para lidar com as situações estressantes (FOLKMAN; LAZARUS, 1985). De maneira geral, as pesquisas relatam que o coping focado no problema tem mais ligação com o funcionamento saudável; enquanto que o uso do coping focado na emoção é relacionado a uma adaptação pobre (Cf. COMPAS et al., 1988; EBATA; MOOS, 1991; GRIFFITH; DUBOW; IPPOLITO, 2000).

Crianças e adolescentes são menos habilidosos em enfrentar os estressores, mostrando mais problemas emocionais/comportamentais (LAZARUS; FOLKMAN, 1984). Hampel e Petermann (2005) mostraram que crianças e adolescentes usam padrões de estratégias de enfrentamento mal adaptados. Baixo rendimento escolar, comportamento violento e doenças físicas são conseqüências de estratégias de enfrentamento inapropriadas (ALTSHULER; RUBLE, 1989; JEWETT, 1997; LEWIS; FRYDENBERG, 2002; RYAN, 1989; SEIFFGEKRENKE, 2000). Outro aspecto verificado é que as estratégias de enfrentamento mal adaptadas influenciam significativamente o desenvolvimento psicológico em jovens (COMPAS et al., 2001). Esses dados enfatizam as estratégias de enfrentamento como determinantes principais de conseqüências do estresse psicológico, emocional e fisiológico (HENDERSON; KELBEY; ENGEBRETSON, 1992).

No estudo de Frydenberg e Lewis (1991), com adolescentes de 16 a 18 anos que completaram a versão adaptada de The Ways of Coping Checklist (FOLKMAN; LAZARUS, 1985), o sexo feminino utilizou na mesma proporção o coping focado no problema que o sexo masculino, sugerindo que meninos e meninas não diferiram um do outro em relação ao uso de estratégias que focam na mudança do ambiente ou em gerar soluções alternativas. Entretanto, as meninas buscaram mais apoio social e se engajaram mais em pensamentos positivos do que os meninos. Elas preferiram as estratégias de evitação porque acreditavam que a situação não estava em seu controle. Os meninos confrontaram o problema na tentativa de resolvê-lo, estavam mais dispostos a correrem riscos ou a atenuarem mais a situação.

A pesquisa de Williams e McGillicuddy-De Lisi (1999) investigou as estratégias que os adolescentes usavam para lidar com um problema diário por meio do mesmo instrumento. Os adolescentes foram divididos em três grupos segundo a idade: início da adolescência $(M=$ 12 anos), meio da adolescência $(M=15,6$ anos) e final da adolescência ( $M=19,1$ anos). Os adolescentes mais novos preferiram utilizar a estratégia de reavaliação positiva mais do que qualquer outro mecanismo de coping. Aqueles no meio da adolescência usaram resolução de 
problemas, reavaliação positiva, aceitação de responsabilidade e autocontrole. Na adolescência tardia essas estratégias (resolução de problemas, reavaliação positiva, aceitação de responsabilidade e autocontrole) foram unidas pela estratégia de apoio social, a qual foi usada mais significativamente pelos adolescentes mais velhos do os que os mais novos.

Nicholls et al. (2009) destacam a dificuldade em comparar estudos anteriores em razão das diferenças existentes nas definições das categorias de coping, nas idades e nos contextos de estresse nos quais os dados são coletados. Portanto, a literatura aponta uma diversidade muito grande de estratégias nas quais cada autor escolhe as categorias pré-determinadas, baseadas em pesquisas prévias ou por análise de conteúdo. Apesar das possíveis confusões produzidas por diferentes tipologias e conceitualizações nessa área, Boekaerts (1996) faz algumas inferências a partir de estudos realizados com crianças e adolescentes. Segundo o autor, essa faixa etária utiliza uma grande diversidade de resposta de coping; de acordo com o domínio (escolar, familiar, social) são utilizadas respostas diferentes; as estratégias mais freqüentes envolvem o coping ativo (tal como controle do perigo e busca de apoio social) e coping interno (por exemplo: planejamento de solução do problema e distração); as estratégias menos freqüentes envolvem autodestruição, agressão, coping de confronto, afastamento, relaxamento e controle da ansiedade.

A relação entre estratégias de coping e psicopatologia também tem sido estudadas visto que frequentemente há interrelações entre elas (FOLKMAN; MOSKOWITZ, 2004). As estratégias de coping de evitação de emoções e problemas têm sido associadas com altos escores no EAT (Eating Attitudes Test) e também com uma imagem corporal mais negativa (GARFINKEL; NEWMAN, 2001).

Yang, Kim e Yoon (2010) avaliaram a prevalência e a correlação de distúrbios alimentares e comportamentos em adolescentes na Coréia do Sul. Nesse estudo, dois dos instrumentos utilizados foram o EAT e o The Ways of Coping Checklist. Na versão sulcoreana, as subescalas foram alteradas para duas estratégias principais de coping: resolução de problemas (foco no problema e apoio social) e estratégias passivas (pensamento positivo e evitação). Foi encontrada uma associação entre coping passivo e distúrbios alimentares, independente do gênero.

Baigrie e Giráldez (2008) examinaram a ligação entre compulsão alimentar e coping em adolescentes espanhóis que não tinham ainda desenvolvido uma desordem alimentar. Os resultados indicaram que os adolescentes que reportavam compulsão alimentar utilizaram mais estratégias de coping de evitação do que aqueles que não engajavam nesse comportamento. 
Um fator que geralmente é estressante para os adolescentes e que frequentemente necessita de habilidades de coping é a imagem corporal. De acordo com Levine e Smolak (2002), tanto para as meninas quanto para os meninos, um grande número de mudanças no desenvolvimento influenciam e são influenciadas pela imagem corporal, incluindo a puberdade, o surgimento da sexualidade, a formação incipiente da identidade, a intensificação dos papéis por gênero e a exploração das reais possibilidades em vários domínios.

\subsection{IMAGEM CORPORAL}

A imagem corporal é um constructo relativamente recente na literatura, que tem sido operacionalmente definido de acordo com áreas específicas de interesse, não havendo uma integração entre as diversas linhas de pesquisa. Portanto, a definição do conceito de imagem corporal atualmente ainda é complexa e tem diferentes enfoques que abordam os diversos componentes desse constructo.

Os primeiros estudos sobre imagem corporal eram de exclusivo domínio da neuropatologia, a qual investigava o esquema corporal. De acordo com Grogan (2008), esquema corporal é a representação neurológica das dimensões e formas corporais que são organizadas pelas aferências proprioceptivas, cinestésicas e sensoriais. A sua organização permite construir a referência postural na qual as percepções e intenções motoras são integradas, permitindo assim, colocar o corpo em movimento orientado no espaço.

A partir de 1920, Paul Schilder começou a investigar a imagem corporal, dentro de uma abordagem psicossocial, destacando a necessidade da investigação de elementos neurológicos, psicológicos e socioculturais da imagem corporal. Em 1935, ele definiu imagem corporal como “... a figuração de nosso corpo formada em nossa mente, ou seja, o modo pelo qual o corpo se apresenta para nós. (...) O esquema do corpo é a imagem tridimensional que todos têm de si mesmos" (SCHILDER, 1935/1980, p. 11).

Outro importante pesquisador da área foi Seymour Fisher, o qual abordou uma visão psicodinâmica da imagem corporal, publicando diversos livros sobre o tema tais como Body Image and Personality em 1958 junto com Sidney Cleveland, e Body Experience in Fantasy and Behavior em 1970. No entanto, seu trabalho foi obscurecido pelo crescimento predominante da abordagem cognitivo-comportamental no estudo da imagem corporal. 
A partir da década de 90 muitos pesquisadores começaram a investigar a relação dos transtornos alimentares com a imagem corporal, aumentando substancialmente o número de pesquisas nessa área. Assim, com esses estudos aumentaram também os modelos psicológicos da imagem corporal e diferentes definições a ela relacionados tais como:

- satisfação corporal, avaliação da aparência, preocupação corporal, e/ou distorção corporal (THOMPSON et al., 1994);

- imagem corporal como a atitude que uma pessoa tem em relação à autopercepções, cognições, afetos e comportamentos do corpo físico (MUTH; CASH, 1997);

- imagem corporal como relacionada à percepção da pessoa do tamanho, forma e peso (KASHUBECK-WEST; MINTZ; SAUNDERS, 2001);

- associado com as experiências que uma pessoa tem com seu corpo (CASH, 2004).

Portanto, múltiplas definições do constructo imagem corporal surgiram a partir de 1990. Atualmente muitos pesquisadores abordam a imagem corporal como um constructo multidimensional com componentes afetivos, cognitivos e comportamentais (BANFIELD; McCABE, 2002; KOSTANSKI; FISCHER; GUALLANE, 2004; THOMPSON et al., 1994; TIGGEMANN, 2006). De acordo com essa visão, a imagem corporal é a percepção, os sentimentos e os pensamentos do indivíduo sobre o seu corpo (GROGAN, 2008).

No Brasil, a área de imagem corporal começou a ser investigada na década de 90 . Um dos primeiros estudos realizados foi o de Cordás e Castilho (1994), os quais apresentaram a versão em português do Body Shape Questionnaire (BSQ). O objetivo foi avaliar a insatisfação corporal de pacientes com transtornos alimentares. Segundo Conti (2008), o BSQ fornece uma avaliação contínua e descritiva das insatisfações da imagem corporal em populações clínicas e não-clínicas. Atualmente, esse instrumento é um dos mais utilizados nas pesquisas nacionais, principalmente no sexo feminino, em pesquisas sobre comportamento alimentar e imagem corporal.

Outros instrumentos utilizados no Brasil são as escalas de silhuetas. É uma das técnicas mais usadas em estudos populacionais para mensuração dos componentes perceptivo e/ou atitudinal da imagem corporal. Esse tipo de escala consiste em uma sequência de desenhos de corpos, os quais variam as silhuetas de pessoas abaixo do peso a pessoas obesas. Dessa forma, o participante tem que apontar a imagem que mais se aproxima de como se percebe e aquela que mais se aproxima de como gostaria de ser. A discrepância entre as duas medidas fornece ao pesquisador a medida de insatisfação que o participante tem em relação a seu corpo como um todo. Além disso, a discrepância entre as medidas de como o participante se percebe e seu estado nutricional atual (medido pelo Índice de Massa Corporal) avalia a 
exatidão perceptiva do seu estado atual. No entanto, Gardner e Brown (2010) avaliaram diversas escalas de silhuetas existentes e notaram que a maioria não permite a medida da discrepância da percepção corporal, somente de insatisfação corporal. Segundo Gardner e Brown (2010), os investigadores que desejam avaliar a discrepância da percepção corporal em adição à insatisfação corporal irão encontrar poucas escalas que medem ambos; como a BMIbased Silhouette Matching Test (PETERSON; ELLENBERG; CROSSAN, 2003; PETERSON; ORSEGA-SMITH; THOLSTRUP, 2004), Discreet Scale (GARDNER et al., 1999; CAMPAYO et al., 2003), Body Image Assessment Scale -BD (GARDNER; JAPPE; GARDNER, 2009) e Body Image Assessment - Obese (WILLIAMSON et al., 2000).

As escalas de silhuetas têm demonstrado confiabilidade, validade e facilidade na aplicação (CAMPANA; TAVARES, 2009). Existem diversas escalas de silhuetas que variam tanto no número de figuras, formas em que são desenhadas as silhuetas, tamanho e apresentação das escalas. Consequentemente é necessária cautela na comparação entre os estudos existentes, visto que utilizam diferentes escalas de silhuetas e assim apresentam diferenças metodológicas.

Kakeshita, Silva, Zanatta e Almeida (2009) criaram a primeira Escala de Silhuetas Brasileiras, a qual apresentou bons resultados psicométricos. A escala apresenta 15 figuras de silhuetas, tanto para sexo masculino quanto feminino, dispostas em cartões plastificados independentes, com intervalo de $2,5 \mathrm{~kg} / \mathrm{m}^{2}$ entre elas (extremidades da escala relacionadas com o IMC médio de $12,5 \mathrm{~kg} / \mathrm{m}^{2}$ a $47,5 \mathrm{~kg} / \mathrm{m}^{2}$ ). O intervalo de abrangência das figuras da escala garantiu a inclusão de casos extremos de IMC, conferindo amplas possibilidades de utilização clínica e epidemiológica do instrumento (KAKESHITA et al., 2009). Essa escala mede tanto a insatisfação corporal quanto a discrepância da percepção corporal.

Outra escala de silhuetas disponível e validada no Brasil por Scagliusi et al. (2006) é a Escala de Silhuetas de Stunkard (STUNKARD; SORENSON; SCHLUSINGER, 1983). Esta escala é composta por nove figuras, as quais aumentam as formas corporais em termos de gordura corporal. É muito utilizada no Brasil para avaliação da insatisfação corporal. No entanto foi validada apenas para mulheres.

Recentemente, Conti e Latorre (2009) realizaram o estudo de validação da escala de silhuetas de Thompson e Gray (1995) para adolescentes brasileiros. A escala é composta por 18 figuras, sendo 9 de cada sexo, e apresentou bons resultados de validação de constructo e reprodutibilidade.

Outros instrumentos utilizados no Brasil são a técnica do desenho da figura humana (ALMEIDA; LOUREIRO; SANTOS, 2002), a escala de autoavaliação do esquema corporal 
(FARIAS; CARVALHO, 1987), a escala de medida da imagem corporal (SOUTO, 1999), o questionário de autoestima e autoimagem (STEGLISH, 1978), entre outros.

\subsubsection{PERCEPÇÃO CORPORAL}

As discrepâncias perceptuais da imagem corporal são caracterizadas por percepções imprecisas, resultando em relatos de superestimação ou subestimação do tamanho das regiões corporais ou de toda a imagem corporal (CASH; DEAGLE, 1997). McCabe et al. (2006) destaca em seu artigo que a percepção da imagem corporal é proposta como um resultado de dois importantes processos: 1) de fatores sensoriais, tais como intensidade do estímulo, deficiências visuais e fatores atencionais e 2) de fatores não sensoriais, os quais incluem fatores cognitivos e afetivos baseados em crenças individuais, esquemas e um conhecimento anterior sobre o próprio corpo.

É importante mostrar que o interesse nas percepções do corpo, e especificamente nas discrepâncias da percepção, foi desenvolvido pela investigação de desordens clínicas (GLEESON; FRITH, 2006). Bruch (1962), por exemplo, sugeriu que mulheres anoréxicas mostravam uma distorção acentuada na percepção de seus tamanhos corporais - elas se percebem como gordas, mesmo quando elas estão dolorosamente e perigosamente com baixo peso. Em 1973, Slade e Russell investigaram a habilidade de indivíduos com anorexia nervosa e indivíduos controles (sem desordem alimentar) em estimar apuradamente suas dimensões corporais (tais como cintura, face, quadril e busto). Para isso utilizaram um aparato referido como "movable caliper technique", no qual os participantes tinham que ajustar a projeção de vários pontos de seus corpos até que a forma projetada estivesse compatível com a percepção dele do próprio corpo. A diferença entre a largura do corpo estimado e o atual era usada como o índice de acurácia (THOMPSON; GARDNER, 2002). Os resultados de Slade e Russell (1973) mostraram que indivíduos com anorexia nervosa superestimaram mais seus tamanhos corporais do que o grupo controle.

A partir do estudo de Slade e Russell surgiram várias pesquisas investigando o componente perceptual da imagem corporal, criando inúmeras variações da técnica original. Com o tempo, os pesquisadores começaram a investigar também outros componentes da imagem corporal levando temporariamente a uma falta de interesse no aspecto perceptual da 
imagem corporal. Esse declínio no interesse do componente perceptual ocorreu, de acordo com Thompson e Gardner (2002), devido aos seguintes fatores:

a) Os pesquisadores começaram a investigar os indivíduos sem transtorno alimentar e notaram que eles reportavam infelicidade subjetiva com sua aparência e o tópico do transtorno dismórfico corporal começou a aparecer com muita freqüência na literatura.

b) Os investigadores começaram a notar que a superestimação corporal e o distúrbio subjetivo não eram altamente correlacionados, e a variável infelicidade subjetiva com a aparência pareceu ser uma melhor variável preditora do funcionamento psicológico (auto-estima, depressão) do que o distúrbio perceptual.

c) Vários estudos experimentais notaram que o componente perceptual previamente tido como estático e não modificável era ao invés disso uma dimensão da imagem corporal afetada por vários fatores contextuais tais como repetição do teste, consumo de alimento durante a sessão de teste, variações na luz, entre outros.

Assim, houve um declínio no interesse da investigação da percepção corporal e um aumento na exploração da insatisfação corporal. Apesar disso, alguns pesquisadores mantiveram o interesse no componente perceptual, realizando mudanças nas metodologias ${ }^{1}$.

Em algumas escalas de silhuetas, por exemplo, alguns pesquisadores aumentaram o número de silhuetas no instrumento (GARDNER; JAPPE; GARDNER, 2009; KAKESHITA et al., 2009), que era um problema que poderia resultar em uma imprecisão na medida e inflar os escores de confiabilidade teste-reteste. Outros problemas observados por Thompson e Gray (1995) em relação às escalas dizem respeito a representações não reais da forma humana, incluindo desproporcionalidade dos braços e pernas, espessura dos braços direito e esquerdo e método de apresentação, geralmente envolvendo um papel com as figuras ordenadas da esquerda para direita.

Os resultados da escala BIAS-BD (GARDNER; JAPPE; GARDNER, 2009) realizada com universitários demonstra que tanto os homens quanto as mulheres superestimaram seu tamanho corporal. Nessa pesquisa os participantes reportaram seu peso atual e altura. Dessa forma, como cada figura corresponde a um IMC específico, a escolha do respondente pôde ser comparada ao IMC atual para determinar uma indicação de tamanho corporal super ou subestimado. No entanto, essa foi uma limitação do estudo visto que as medidas para o cálculo do IMC não foram aferidas pelos pesquisadores e sim reportadas pelos participantes.

\footnotetext{
${ }^{1}$ Cf. GARDNER et al., 1989; SMEETS et al., 1999; GARDNER; JONES; BOKENKAMP, 1995
} 
Em muitos estudos é utilizada essa metodologia de os próprios participantes reportarem seu peso atual ou de terem que se avaliar em questionários e escalas tipo Likert. Por exemplo, no estudo de Lemon et al. (2009) com indivíduos americanos de 18 a 65 anos, a percepção do peso foi realizada por meio de uma escala de sete pontos ("muito abaixo do peso" a "muito obeso"). Nessa pesquisa, $86 \%$ das mulheres acima do peso e $52 \%$ daquelas com peso normal perceberam-se com sobrepeso. Em relação aos homens, 47\% com sobrepeso se perceberam com peso normal, $25 \%$ dos obesos reportaram-se como sobrepeso ou no peso normal e somente $35 \%$ deles se auto-avaliaram com muito sobrepeso.

$\mathrm{O}$ artigo de Viner et al. (2006) analisou a percepção do peso de adolescentes ingleses de 11 a 14 anos utilizando um questionário que perguntava "dada sua idade e altura, você diria que você está: a) no peso certo, b) muito pesado, c) muito leve ou d) não tem certeza?". Os resultados demonstraram que as meninas significativamente avaliaram mais apropriadamente seu peso corporal do que os meninos com sobrepeso e obesidade. A precisão da percepção do peso diminuiu com o aumento do Índice de Massa Corporal (IMC) nos meninos (60\% dos meninos com sobrepeso e 30\% obesos avaliaram-se como no "peso certo") enquanto que nas meninas essa precisão foi maior de acordo com o aumento do IMC (34\% com sobrepeso e $9 \%$ com obesidade avaliaram-se como no peso certo).

Outra pesquisa avaliou 4167 adolescentes ingleses (STANDLEY; SULLIVAN; WARDLE, 2009). Os participantes avaliaram seu peso percebido em uma escala de cinco pontos ("muito magro" a "muito gordo"). As respostas a essa escala foram altamente correlacionadas com a escolha da figura atual na escala Contour Drawing Rating Scale de Thompson e Gray (1995). Na amostra, a subestimação (sentir-se "no peso certo" ou "magro" enquanto que de fato estava com sobrepeso ou obesidade) pareceu mais comum do que a superestimação (sentir-se gordo enquanto de fato estava no peso saudável ou baixo peso). Os resultados mostram que $43 \%$ das meninas e $24 \%$ dos meninos se descreveram como "gordos"

No estudo de Peterson, Ellenberg e Crossan (2003), com a escala de silhueta BMIBased Silhouette Matching Test, foram avaliados 172 adolescentes americanos com idade entre 13 a 17 anos. Ambos os sexos superestimaram seu tamanho corporal: no sexo feminino a imagem percebida como atual $\left(23,61 \mathrm{~kg} / \mathrm{m}^{2}\right)$ foi significativamente maior do que o IMC reportado $\left(22,28 \mathrm{~kg} / \mathrm{m}^{2}\right)$ assim como no sexo masculino a imagem percebida como atual $\left(25,13 \mathrm{~kg} / \mathrm{m}^{2}\right)$ foi maior que o IMC reportado $\left(23,39 \mathrm{~kg} / \mathrm{m}^{2}\right)$.

No Brasil, Kakeshita e Almeida (2006), avaliando a percepção corporal de 116 universitários com a Escala de Silhuetas desenvolvida por eles, mostraram que a maioria das mulheres eutróficas e com sobrepeso superestimaram seu tamanho corporal $\left(3,4 \mathrm{~kg} / \mathrm{m}^{2}\right.$ e 1,9 
$\mathrm{kg} / \mathrm{m}^{2}$, respectivamente) enquanto mulheres obesas e homens subestimaram o tamanho corporal (sexo feminino com obesidade $=-0,7 \mathrm{~kg} / \mathrm{m}^{2}$; sexo masculino eutrófico $=-1,2 \mathrm{~kg} / \mathrm{m}^{2}$, sobrepeso $=-1,5 \mathrm{~kg} / \mathrm{m}^{2}$ e obeso $=-2,2 \mathrm{~kg} / \mathrm{m}^{2}$ ).

Laus (2009) utilizando a mesma escala em uma amostra de 275 adolescentes, com idade entre 14 a 17 anos, na cidade de Ribeirão Preto-SP, encontrou uma média de discrepância da percepção corporal entre as meninas de $3,5 \mathrm{~kg} / \mathrm{m}^{2}$ e entre os meninos de 3,8 $\mathrm{kg} / \mathrm{m}^{2}$. O estudo apontou uma diferença significativa entre as categorias de estado nutricional, tendo o grupo de indivíduos com baixo peso obtido os menores índices de discrepância da percepção corporal, indicando um aumento na discrepância conforme o aumento do IMC, em ambos os sexos.

Branco, Hilário e Cintra (2006), analisaram a percepção corporal em 1009 adolescentes de 14 a 19 anos da cidade de São Paulo por meio da escala de silhuetas de Madrigal-Fritsch et al. (1999). Essa escala tem nove silhuetas na qual são estabelecidas quatro categorias: baixo peso (silhueta 1), eutrofia (silhuetas 2 a 5), sobrepeso (silhuetas 6 e 7) e obesidade (silhuetas 8 e 9). Os pesquisadores notaram que para ambos os sexos a percepção real de sua condição é distorcida, sendo que nas meninas há mais casos de superestimação e nos meninos de subestimação da condição real. Os resultados mostram que 43,6\% das meninas eutróficas se identificaram com algum excesso de peso, 47,6\% com sobrepeso se acharam obesas. E em relação aos meninos, apenas 19,2\% daqueles eutróficos se acharam com sobrepeso enquanto que $26,3 \%$ com sobrepeso consideraram-se com peso normal, e $42,8 \%$ dos obesos identificaram-se como sobrepeso.

Portanto, são encontrados diferentes resultados na literatura de percepção da imagem corporal. Essas contradições e inconsistências entre as pesquisas podem ser compatíveis com diferenças metodológicas dos estudos (MONTEATH; McCABE, 1997). Além disso, é importante fazer uma ressalva: a superestimação ou subestimação do tamanho e/ou forma do corpo não se constitui uma característica particular de adolescentes que desenvolvem algum tipo de transtorno alimentar, uma vez que este processo está presente na dinâmica vivencial dos indivíduos dessa faixa etária (CONTI, 2002). 


\subsubsection{INSATISFAÇÃO CORPORAL}

Além da presença de discrepâncias na percepção corporal, estudos sugerem que a diferença entre o corpo ideal e real pode resultar em insatisfação corporal (DURKIN; PAXTON, 2002), a qual tem mostrado uma alta prevalência na adolescência (KOSTANSKI; FISCHER; GUALLANE, 2004; RICCIARDELLI; McCABE, 2001), principalmente entre as meninas (BARKER; GALAMBOS, 2003; EISENBERG; NEUMARK-SZTAINER; PAXTON, 2006; KNAUSS; PAXTON; ALSAKER, 2007). Ricciardelli e McCabe (2001), em um artigo de revisão da literatura abordando trabalhos feitos na Austrália, Croácia, Inglaterra, México, Suíça e Estados Unidos com crianças utilizando a metodologia de escalas silhuetas, demonstraram que entre $28 \%$ a $55 \%$ das meninas desejam um tamanho corporal menor enquanto entre os meninos, $13 \%$ a $48 \%$ desejavam um corpo maior.

No estudo de Sabbah et al. (2009) com adolescentes (idade de 11, 13 e 15 anos) de 24 países das regiões da Europa, Canadá e Estados Unidos, a insatisfação corporal foi altamente prevalente e mais comum entre meninas do que meninos. Nesse estudo as categorias de satisfação e insatisfação foram derivadas a partir da seguinte questão: "No presente momento você está em dieta ou fazendo algo para perder peso?”. Os respondentes que selecionaram “não, meu peso está bom” foram classificados como satisfeitos com o peso; os respondentes que selecionaram tanto "não, mas eu preciso perder peso" ou "sim" foram classificados como insatisfeitos com o peso. Altas avaliações de insatisfação corporal entre os meninos foram encontradas na Itália (39.9\%), Estados Unidos (37.7\%), e Grécia (35.2\%), enquanto que entre as meninas, as maiores taxas de insatisfação corporal foram encontradas na República Tcheca (61.8\%), Eslovênia (56.8\%) e Itália (55.2\%).

Mellor et al. (2009) em um contexto oriental investigou a insatisfação corporal em adolescentes da Malásia, China e Índia, com idade entre 12 a 18 anos. Para avaliação da insatisfação corporal foi utilizada uma versão abreviada da Body Dissatisfaction Scale (McCABE; RICCIARDELLI, 2004), a qual inclui cinco itens que pedem para os respondentes indicarem em uma escala Likert de cinco pontos ("muito feliz" a "muito infeliz") o quão satisfeitos estavam como o seu peso, músculos, parte inferior, do meio e posterior do corpo. Os resultados demonstraram que as adolescentes chinesas estavam mais insatisfeitas com seus corpos do que os adolescentes chineses, enquanto que as meninas malaias e indianas não reportaram uma insatisfação corporal maior que seus pares masculinos. 
No Brasil, estudos também descreveram alta prevalência de insatisfação com o corpo em crianças, adolescentes, jovens e adultos. No estudo realizado no interior do Rio Grande do Sul por Triches e Giugliani (2007), com a escala Children's Figure Rating Scale (TIGGEMANN; WILSON-BARRET, 1998) em escolares de 8 a 10 anos, a insatisfação corporal estava presente em $63,9 \%$ da amostra. Entre as meninas com insatisfação corporal, $71 \%$ queriam ser mais magras e 28,9\% gostariam de ganhar peso. Em relação aos meninos insatisfeitos, 52,5\% gostariam de ser mais magros e 47,5\% desejavam ser mais gordos. Outro estudo realizado na capital do mesmo estado por Pinheiro e Giugliani (2006) e com o mesmo instrumento, mostrou que a insatisfação corporal estava presente em $82 \%$ dos escolares de 8 a 11 anos. Entre as meninas, 55\% desejavam um corpo mais magro e entre os meninos, 38\% desejavam um corpo maior.

Em Minas Gerais, Fernandes (2007) realizou sua pesquisa com 635 crianças com idade entre 6 a 13 anos e 548 adolescentes com idade entre 14 e 18 anos. Os resultados mostram que $63,4 \%$ das crianças e $61,7 \%$ dos adolescentes estavam insatisfeitos com o corpo. Observou-se que entre os meninos insatisfeitos com o corpo, 54,6\% gostariam de ser mais magros e 45,4\% desejavam ser mais gordos. Entre as meninas com insatisfação corporal, 53,2 queriam ser mais magras e $46,8 \%$ gostariam de ganhar peso.

Outro estudo que utilizou a mesma escala de silhuetas de Stunkard usada na pesquisa anterior foi realizado em Florianópolis. Adami et al. (2008) pesquisou 242 adolescentes com idade média de 14 anos e encontrou uma alta percentagem de adolescentes insatisfeitos: 69\% do sexo masculino e $76,7 \%$ do sexo feminino. Os meninos demonstraram tanto uma tendência em aumentar a sua silhueta corporal quanto em diminuir. Por sua vez, as meninas demonstraram querer diminuir a sua silhueta corporal.

Pelegrini e Petroski (2009) avaliaram 595 adolescentes com idade entre 14 a 18 anos no Oeste de Santa Catarina e norte do Rio Grande do Sul com a escala de silhuetas de Stunkard. Os dados também mostram uma alta prevalência de insatisfação corporal em ambos os sexos (71,9\% dos meninos e $61,9 \%$ das meninas insatisfeitos), sendo que os adolescentes do sexo masculino desejavam aumentar o tamanho da silhueta corporal $(41,3 \%)$, enquanto as do sexo feminino desejavam reduzir $(50,5 \%)$.

No interior paulista, em um estudo realizado com a escala de silhuetas de Kakeshita et al. (2009) por Laus (2009), foi avaliado a insatisfação corporal em 275 adolescentes do ensino médio de escolas públicas e particulares. Os resultados mostram que a média do IMC escolhido como Ideal (como o indivíduo gostaria de ser) foi de $24,3 \mathrm{~kg} / \mathrm{m}^{2}$ no sexo feminino e $24,2 \mathrm{~kg} / \mathrm{m}^{2}$ no sexo masculino. Já a figura escolhida como Atual (como o indivíduo se vê) foi 
de $25,2 \mathrm{~kg} / \mathrm{m}^{2}$ no grupo feminino e $25,8 \mathrm{~kg} / \mathrm{m}^{2}$ no grupo masculino. Portanto, com relação à insatisfação corporal, tanto as meninas quanto os meninos gostariam de ter corpos menores $\left(-1 \mathrm{~kg} / \mathrm{m}^{2}\right.$ e $-1,3 \mathrm{~kg} / \mathrm{m}^{2}$, respectivamente). Não houve diferença de sexo na insatisfação corporal e sim entre os diferentes estados nutricionais dos adolescentes, indicando que a insatisfação aumenta progressivamente conforme aumenta o estado nutricional em ambos os sexos.

Em relação aos adultos brasileiros, as pesquisas realizadas com a escala de silhuetas de Stunkard também mostram uma prevalência de insatisfação corporal. Coqueiro et al. (2008) encontrou na amostra com adultos, com idade média de 23 anos, que 78,8\% estavam insatisfeitos (maior proporção no sexo feminino para o desejo de reduzir as dimensões corporais enquanto que no sexo masculino existiu um desejo maior para aumentar). Por fim, Quadros et al. (2010) também encontrou uma alta percentagem de insatisfação em adultos com média de idade de 20 anos (77,4\% dos sexo masculino e $77,8 \%$ dos sexo feminino apresentavam insatisfação corporal), sendo que o sexo masculino apresentou maior prevalência de insatisfação por magreza enquanto que seus pares do sexo feminino relataram maior insatisfação por excesso de peso.

Recentemente, Alvarenga et al. (2010) avaliaram a insatisfação corporal em 2.402 universitárias do sexo feminino em cinco regiões do Brasil utilizando a escala de silhuetas de Stunkard. A maioria das universitárias $(64,4 \%)$ desejava ser menor do que é, atestando grande magnitude de insatisfação corporal nesse grupo. Em média, as estudantes escolheram como "saudável" figuras maiores do que as que escolheram como "ideal". Estudantes de baixo peso escolheram figuras "ideal" e "saudável" menores do que as "atuais". Algo que os autores chamam a atenção é em relação ao grande número de estudantes eutróficas que escolheram como "ideal" e "saudável" números menores do que a figura atual, evidenciando que a insatisfação corporal é grande, mesmo naquelas de peso normal. Além disso, notam-se algumas diferenças regionais: estudantes do Norte tiveram os ideais mais magros e as do Centro-Oeste, os maiores ideais para corpo saudável e desejável.

Portanto, de maneira geral, há uma tendência da insatisfação corporal no sexo feminino ser em grande parte relatada em relação a um desejo de ser mais magra, enquanto que no sexo masculino a insatisfação corporal ela ser relacionada principalmente ao desejo de aumentar o tamanho corporal (SMOLAK; STEIN, 2006; COHANE; POPE, 2001). 


\subsubsection{FATORES QUE INFLUENCIAM A IMAGEM CORPORAL}

Os fatores ambientais têm um forte impacto no desenvolvimento e na manutenção da imagem corporal por meio da criação de uma cultura que valoriza, reforça e modela ideais culturais de beleza e forma corporal, e pune de variadas formas aqueles que não seguem esse padrão pré-estabelecido.

Três fatores ambientais têm sido tipicamente identificados, os quais são pais, pares e a mídia. Muitos estudos propõem que essas formas de influência, quando combinadas, são fortes preditivos de preocupações com o peso e formas corporais (DUNKLEY; WERTHEIM; PAXTON, 2001; LEVINE; SMOLAK; HAYDEN, 1994; PETERSON; PAULSON; WILLIAMS, 2007).

Segundo o estudo de Field et al. (2001), que envolveu uma grande amostra de adolescentes, as influências dos pais são uma importante forma de pressão, independentemente da influência da mídia e dos pares, na predição de preocupações com o peso ou dieta constante. O estudo de revisão de Rodgers e Chabrol (2009) também mostra que a influência parental, via mensagens verbais e encorajamento ativo, tem mostrado ter um forte impacto nas preocupações corporais e nos comportamentos alimentares dos filhos.

Sabbah et al. (2009) investigou o quanto a percepção dos adolescentes a respeito da dificuldade em conversar com os pais estaria associado com insatisfação corporal. Diferenças de gênero na relação entre comunicação com os pais e insatisfação corporal foram particularmente notáveis nesse estudo. A dificuldade em conversar com a mãe foi associada com insatisfação corporal entre as meninas, mas não entre os meninos, enquanto que a dificuldade em conversar com o pai foi associada com insatisfação corporal entre meninas e meninos. Os pais foram reportados com sendo uma importante influência para os meninos tanto em termos de perda de peso como aumento da massa muscular. Esses resultados sugerem que o envolvimento dos ambos os pais pode ser um importante aspecto no desenvolvimento físico e emocional dos adolescentes e na prevenção da insatisfação corporal.

Estudos mostram que os colegas também são considerados uma influência sociocultural importante na formação da imagem corporal. As experiências com os pares, incluindo conversas ou críticas, contribuem de forma significativa na internalização da imagem corporal, tanto para meninas quanto para meninos (JONES; VIGFUSDOTTIR; LEE, 2004). Já Dohnt e Tiggemann (2006) apontam que as meninas possuem a percepção de que a 
insatisfação dos colegas em relação à sua forma corporal é um fator preditivo para a sua própria insatisfação corporal e engajamento em dietas.

Por fim, o terceiro fator ambiental muito investigado é a mídia. Segundo Dittmar (2009) a mídia é vista particularmente como uma forma potente e sutil de influência, sendo que uma série de estudos mostra a exposição da mídia e a insatisfação corporal. A maioria dessas pesquisas tem sido realizada com mulheres e garotas, as quais têm como ideal um corpo bem magro, e cujos modelos da mídia são tipicamente de baixo peso. Recentemente começaram os estudos com homens e garotos, para os quais a mídia começou a retratar o ideal corporal com aumento da massa muscular (POPE et al., 1999).

Três meta-análises recentes mostram o efeito geral negativo do "corpo perfeito" da mídia na imagem corporal de homens e mulheres. Barlett, Vowels e Saucier (2008) reportaram, em uma meta-análise com homens, uma associação significativa entre imagem corporal negativa e o consumo de imagens de homens ideais na mídia em 15 estudos correlacionais, assim como uma imagem corporal negativa maior depois da exposição direta a tais imagens em 10 experimentos. Para mulheres, uma meta-análise de 25 estudos experimentais encontrou que elas se sentiram pior sobre seus corpos depois da exposição a imagens ideais de magreza do que a outros estímulos (GROEZ; LEVINE; MURNEN, 2002). Uma extensão recente incluiu 49 experimentos e 28 estudos correlacionados, e novamente encontraram que a exposição ao ideal da mídia de magreza é ligado à preocupações das mulheres com a imagem corporal, com significância para insatisfação corporal, comportamentos alimentares e crenças (GRABE; WARD; HYDE, 2008).

\subsubsection{CONSEQÜENCIAS DA IMAGEM CORPORAL PARA A SAÚDE}

A área da imagem corporal envolve uma série de conseqüências para a saúde devido à maior possibilidade do estabelecimento de comportamentos não saudáveis em busca de um ideal corporal que muitas vezes é incompatível com a biologia do ser humano.

Estudos confirmam que a insatisfação corporal ou a imagem corporal negativa pode ser entendida como um dos mais consistentes e significantes precursores da autopercepção negativa, estados emocionais negativos, e comportamentos não saudáveis relacionados ao corpo (GRABE; WARD; HYDE, 2008). 
A insatisfação corporal, a experiência de pensamentos negativos e a autoestima corporal estão associadas a uma gama de problemas de saúde físicos e mentais, incluindo transtornos alimentares, obesidade, transtorno dismórfico corporal, depressão e baixa autoestima (HOLSEN; KRAFT; ROYSAMB, 2001; JOHNSON; WARDLE, 2005; STICE; BEARMAN, 2001; POLIVY; HERMAN, 2002; THOMPSON, 2004), aumento da ansiedade e de comportamentos de risco como tabagismo, alcoolismo e abuso de substâncias (McCABE; RICCIARDELLI; BANFIELD, 2001; CAHILL; MUSSAP, 2007). Também estão relacionados ao aumento de comportamentos de modelação corporal com potenciais conseqüências não saudáveis, tais como cirurgia cosmética, regimes de dieta não balanceados e abuso de esteróides (CAFRI et al., 2005; GROGAN, 2008).

As adolescentes têm medo de engordar e, em conseqüência, desejam um controle do seu peso (NEUMARK-SZTAINER et al., 1999). Esta angústia por engordar é em parte independente do peso real (BENEDIKT; WERTHEIN; LOVE, 1998; PARHAM; 1999). Alguns autores descrevem que os padrões impostos pela sociedade podem influenciar negativamente o consumo alimentar principalmente no sexo feminino, visto que, para se manterem dentro dos padrões de beleza, as adolescentes chegam a omitir refeições importantes como o café da manhã ou o jantar, acarretando no baixo consumo de energia e proporção inadequada entre os nutrientes (ANDERSEN et al., 1995; BARKER; THOMPSON; McCLEAN, 1995; GAMBARDELLA; FRUTUOSO; FRANCHI, 1999). No sexo masculino, a conseqüência de uma maior preocupação com os músculos está levando muitos indivíduos a utilizarem técnicas de modelação de corpo, tais como anabolizantes e suplementos alimentares (SMOLAK, 2004).

Outra conseqüência preocupante para a saúde, de como os indivíduos avaliam sua imagem corporal, é o aumento do risco de ideação suicida. Dave e Rashad (2009) estudaram a relação entre a percepção de estar com sobrepeso e comportamentos suicidas em adolescentes americanos. Os resultados indicaram que a insatisfação corporal teve um forte impacto em todos os comportamentos suicidas para as meninas. Os resultados não foram significativos para os meninos. Uma pesquisa realizada na Coréia do Sul com adolescentes analisou a contribuição da insatisfação corporal para a ideação suicida, de acordo com gênero. Os resultados de Kim (2009) apontaram que a insatisfação corporal contribuiu para a ideação suicida em ambos os gêneros. Tal associação ocorreu para todos estados nutricionais, e os meninos com baixo peso e meninas com peso normal insatisfeitos com seus corpos foram os grupos com maiores ideações suicidas. 
Dadas essas importantes conseqüências para a saúde, destaca-se que imagem corporal é um aspecto fundamental do bem-estar físico e mental do adolescente e por isso se torna imperativo o aumento do entendimento dos fatores de risco e os processos psicológicos que podem levar à inacurácia da percepção corporal e insatisfação corporal. Assim, é interessante a investigação da influência dos sintomas de estresse nessa fase e de como os adolescentes enfrentam os estressores relacionados à questão da imagem corporal.

Atualmente não há estudos realizados com adolescentes que tenham investigado o estresse, as estratégias de coping utilizadas por adolescentes em uma situação de desconforto com o próprio corpo e a imagem corporal, avaliando também o estado nutricional. 


\section{OBJETIVO}

O presente estudo teve como objetivo investigar o estresse, as estratégias de enfrentamento utilizadas em uma situação envolvendo desconforto com o corpo, a imagem corporal e o estado nutricional em adolescentes matriculados em escolas públicas do ensino médio do município de Ribeirão Preto-SP. 


\section{MÉTODO}

\subsection{PARTICIPANTES}

O estudo realizado é uma pesquisa do tipo metodológica, de corte transversal de uma amostra por conveniência de alunos regularmente matriculados em três escolas da rede pública do Ensino Médio, no município de Ribeirão Preto-SP, nos anos 2008 e 2009. Participaram da pesquisa 213 adolescentes, na faixa etária de 15 a 18 anos, sendo 47 participantes do sexo masculino e 166 do sexo feminino. Os adolescentes eram convidados a participarem do estudo por meio de uma exposição sobre a pesquisa em sala de aula pela pesquisadora. Após a exposição, foi entregue uma carta que esclarecia os objetivos e procedimentos da pesquisa com o Termo de Consentimento Livre e Esclarecido (ANEXO 1). Participaram da pesquisa os adolescentes que entregaram a carta devidamente assinada pelo responsável. O presente estudo está de acordo com as normas no. 196 de 10/10/1996 do Conselho Nacional de Saúde e foi aprovado pelo Comitê de Ética da FFCLRP-USP (Processo CEP-FFCLRP no. 369/2007- 2007.1.2413.59.9) [ANEXO 2]. A participação foi voluntária e a coleta de dados ocorreu em uma sala restrita, disponibilizada pela direção escolar.

O nível socioeconômico foi avaliado pelo Critério Padrão de Classificação Econômica Brasil (CCEB, 2008) [ANEXO 3]. Esse instrumento divide a população em oito classes, de acordo com a distribuição de renda: A1, A2, B1, B2, C1, C2, D e E. Para chegar a essa classificação, o instrumento pontua de acordo com a posse de certos itens (exemplo: televisão em cores, DVD, geladeira, automóvel, entre outros) e grau de instrução do chefe de família. A maioria dos participantes pertencia às classes econômicas C1 (35,7\%), B2 (31\%) e C2 $(16,4 \%)$.

Por fim, o Índice de Massa Corporal (IMC) ou Índice de Quetelet foi obtido dividindose o peso, em quilogramas, pela estatura ao quadrado, em metros (GARROW; WEBSTER, 1985). Para pesar o participante, foi utilizada uma balança eletrônica com capacidade para $150 \mathrm{~kg}$ e com definição de medida de $50 \mathrm{~g}$. A balança foi colocada em local plano e os participantes foram pesados sem sapatos, agasalhos ou objetos nos bolsos. Para aferir a estatura, um antropômetro vertical foi usado. Os participantes foram solicitados a ficarem descalços, com os pés paralelos e tornozelos unidos; as nádegas, os ombros e a parte posterior da cabeça encostados na parede, estando os braços soltos ao longo do corpo. Portanto, o 
participante permaneceu em pé, ereto, sem encolher ou esticar, olhando para frente. A barra horizontal foi abaixada até repousar no topo da cabeça. A leitura foi efetuada o mais próximo de 0,5 cm. Posteriormente, a medida do IMC foi classificada em percentil, segundo sexo e idade, para avaliação do estado nutricional de acordo com a fase da adolescência. Os padrões utilizados como referências são da Organização Mundial da Saúde (DE ONIS et al., 2007), que estabelece: $\mathrm{P}<3$ (baixo peso), $\mathrm{P} \geq 3$ e $\mathrm{P}<85$ (eutrófico), $\mathrm{P} \geq 85$ e $\mathrm{P}<97$ (sobrepeso) e $\mathrm{P} \geq 97$ (obesidade). Os adolescentes que participaram da pesquisa, em sua maioria, foram classificados como eutróficos (91\%), enquanto que 2,35\% eram baixo peso, 4,7\% sobrepeso e $1,85 \%$, obesos. As características da amostra estão apresentadas na Tabela 1 , na sessão resultados.

\subsection{MEDIDAS}

\subsubsection{ESTRESSE}

O instrumento utilizado para avaliar o estresse foi o Inventário de Sintomas de Stress para Adultos de LIPP (ISSL) - validado para participantes a partir de quinze anos (LIPP, 2000). O ISSL (ANEXO 4) leva cerca de dez minutos para ser administrado e é composto por três quadros que se referem às quatro fases do estresse, divididos de forma temporal em sintomas das últimas 24 horas (Fase de Alarme - Quadro 1), última semana (Fase de Resistência e Quase-Exaustão - Quadro 2) e último mês (Fase de Exaustão - Quadro 3). A sintomatologia é dividida em física e psicológica, correspondentes às manifestações mais freqüentes do estresse sentidas pelos participantes que vivenciam uma situação potencialmente estressora. O diagnóstico positivo é dado a partir da soma dos sintomas de cada quadro do inventário, sendo que ao atingir o número limite para uma fase específica, concebe-se que o participante tem estresse, esclarecendo qual a fase que ele se encontra e se pode estar evoluindo para estágios mais graves do estresse (LIPP, 2000). Portanto, esse instrumento avalia se o participante tem estresse, quais os sintomas de estresse predominantes (se físicos, psicológicos ou ambos) e qual a fase do estresse em que o participante se encontra (alerta, resistência, quase-exaustão e exaustão). 


\subsubsection{COPING}

Adaptado no Brasil por Savóia, Santana e Mejias (1996), o Inventário de Estratégias de Coping de Folkman e Lazarus (1985) foi utilizado para investigar as estratégias de enfrentamento utilizadas pelos participantes em uma situação de desconforto com o próprio corpo (ANEXO 5). Cada administração do questionário centraliza-se no processo de coping de uma situação particular e não no coping como estilos ou traços de personalidade. A situação é que determina o padrão de estratégias de coping, e não variáveis pessoais. O Inventário é composto por 66 itens, em que a resposta a cada item é registrada a partir de uma escala Likert de zero ("não usei esta estratégia") a 3 ("usei em grande quantidade"). As estratégias de enfrentamento são: confronto, afastamento, autocontrole, suporte social, aceitação de responsabilidade, fuga e esquiva, resolução de problemas e reavaliação positiva. A escala não apresenta pontuação total como somatória para avaliação, sendo que os itens devem ser avaliados por meio dos escores médios dentro de cada estratégia (FOLKMAN et al., 1986). Portanto, para a análise dos dados, foram somados os escores atribuídos a cada item de um mesmo fator e divididos pelo número total de itens, identificando assim os fatores de coping utilizados pelos adolescentes para enfrentar o estresse.

As correlações obtidas na validação para o Brasil apresentaram valores de 0,424 a 0,688 (SAVÓIA; SANTANA; MEJIAS, 1996). O alfa de Cronbach foi calculado para verificar a consistência interna dos fatores de coping na presente pesquisa. $O$ valor do coeficiente alfa de Cronbach foi entre 0,81 a 0,84 , o que indica uma boa homogeneidade e consistência dos itens.

Folkman e Lazarus (1988) também propuseram a divisão dos fatores de coping em outras duas subescalas, da seguinte forma: enfrentamento focado no problema (confronto e resolução de problemas) e enfrentamento focado na emoção (afastamento, autocontrole, aceitação de responsabilidade, reavaliação positiva, fuga e esquiva). O fator suporte social engloba ambos.

\subsubsection{IMAGEM CORPORAL}

Por intermédio da Escala de Figuras de Silhuetas (Figura 1) - desenvolvida e validada para a população brasileira por Kakeshita, Silva, Zanatta e Almeida (2009) - foram avaliadas a acurácia da percepção corporal e a insatisfação corporal. Esse instrumento é composto por 
15 cartões de cada gênero, nos quais as silhuetas das figuras variam do $\mathrm{IMC}=12,5 \mathrm{~kg} / \mathrm{m}^{2}$ ao $\mathrm{IMC}=47,5 \mathrm{~kg} / \mathrm{m}^{2}$, com diferença constante de 2,5 pontos entre os cartões. Primeiramente os cartões são dispostos em série ordenada ascendente. Depois é solicitado ao participante que escolha um cartão com a silhueta que mais se aproxima da imagem que ele tem de seu próprio corpo no momento (IMC Atual). Anotada a escolha, o participante indica o cartão com a silhueta que gostaria de ter (IMC Desejado).

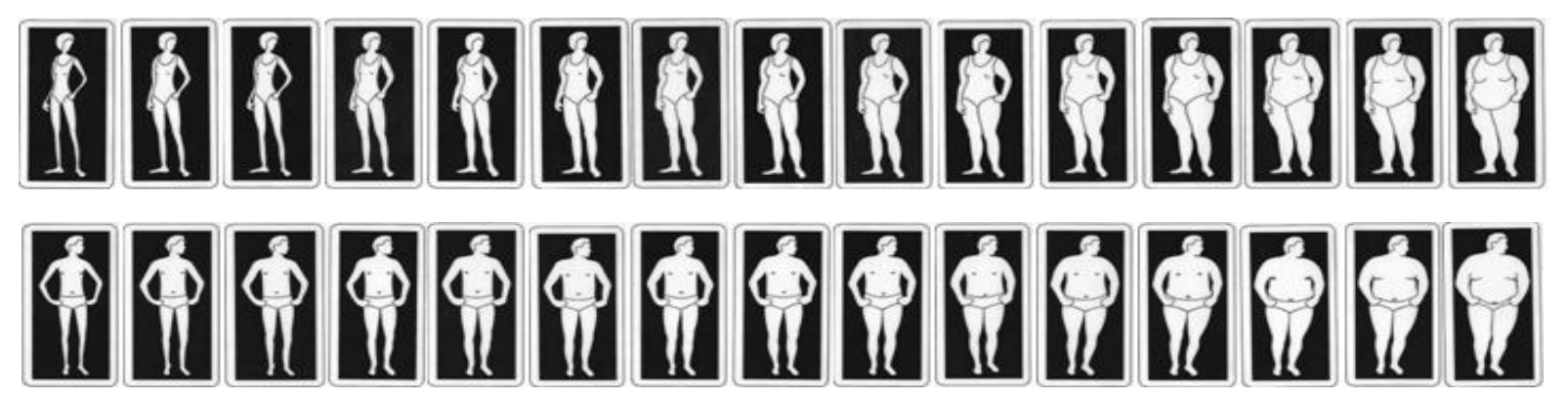

Figura 1 - Escala de figuras de silhuetas para mulheres e homens.

Para tabulação e análise dos dados, foram considerados os IMC correspondentes às figuras escolhidas (IMC Atual e IMC Desejado), os quais foram comparados ao IMC Real, aferido durante a coleta. Portanto, para o cálculo da acurácia da percepção corporal, subtrai-se do IMC Atual o IMC Real; e para o cálculo da insatisfação corporal, subtrai-se do IMC Desejado o IMC Atual.

$$
\begin{gathered}
\text { Acurácia da percepção corporal = IMC “Atual” - IMC Real } \\
\text { Insatisfação = IMC “Desejado” - IMC “Atual” }
\end{gathered}
$$

\subsection{PROCEDIMENTO}

Após a entrega do Termo de Consentimento Livre e Esclarecido para a pesquisadora, devidamente assinado pelo responsável do participante consentindo a participação deste na pesquisa, iniciou-se a coleta de dados realizada individualmente. 
Para todos os participantes obedeceu-se a seguinte ordem de aplicação dos instrumentos: 1) Questionário Socioeconômico, 2) Inventário de Sintomas de Stress, 3) Inventário de Estratégias de Enfretamento, 4) Escala de Figuras de Silhuetas e 5) Aferimento de peso e altura. Solicitou-se aos participantes uma leitura atenta das instruções dos instrumentos para em seguida realizar o preenchimento das respostas. O tempo gasto para realizar a coleta foi de aproximadamente 40 minutos e todos os instrumentos foram aplicados no mesmo e único encontro.

\subsection{ANÁLISE DOS DADOS}

Uma análise descritiva foi realizada para todas as variáveis relevantes do estudo. Análises de Variância (ANOVA) compararam as variáveis inacurácia da percepção corporal, insatisfação e coping por sexo, estado nutricional e estresse. Para análise da diferença entre os grupos, foi utilizado o pós-teste de Duncan. Além disso, o Teste "Exato de Fisher" comparou os fatores de coping (categorizado em 0, 1, 2 e 3) por sexo, estado nutricional e estresse. Por meio desse teste também foram comparadas as variáveis inacurácia da percepção corporal e insatisfação com sexo, percentil e estresse. Correlações de Pearson mediram a associação linear entre os fatores de coping e também a associação entre inacurácia da percepção corporal e insatisfação corporal. Utilizou-se a Análise de Regressão Logística Bivariada para estimativa da razão de chances (Odds Ratio) considerando os fatores de coping como variável dependente e as demais variáveis (sexo, estado nutricional, estresse, imagem corporal) como variáveis independentes. O nível de significância adotado foi $\mathrm{p}<0,05$. Os programas utilizados foram o Epi-Info, versão 3.5.1, para cálculo do estado nutricional, e o SAS, versão 9 , para as análises estatísticas. 


\section{RESULTADOS}

Os resultados obtidos na presente pesquisa são apresentados agrupados de acordo com cada variável considerada. No item estresse, as médias obtidas no instrumento são apresentadas, assim como os resultados de estresse por sexo e estado nutricional. $\mathrm{Na}$ variável coping, as médias dos escores obtidos são mostradas por sexo, estado nutricional, estresse e imagem corporal. Na variável imagem corporal, são apresentadas as médias de inacurácia da percepção corporal e insatisfação corporal por sexo e estado nutricional. Por fim, a associação entre as variáveis do estudo realizada por meio das análises estatísticas são devidamente expostas.

\subsection{ESTRESSE}

As médias dos escores no Inventário de Sintomas de Stress (ISSL) estão apresentadas na Tabela 1, de acordo com o sexo e o estado nutricional dos participantes. Observa-se que dos 213 participantes, 55,87\% foram avaliados com estresse. Desses participantes com estresse, aproximadamente 94\% foram classificados como eutróficos. Em relação ao sexo, verificou-se que $61,45 \%$ das meninas apresentaram sintomas de estresse enquanto que nos participantes do sexo masculino a porcentagem foi de $36,2 \%$.

Quanto às fases do estresse, 2,52\% do grupo total encontra-se na fase de alerta, $86,55 \%$ em resistência, $8,41 \%$ na fase de quase-exaustão e $2,52 \%$ na fase de exaustão. Esses dados mostram uma grande incidência na segunda fase do estresse, sendo que a predominância do estado nutricional é eutrofia. No que se refere ao sexo feminino, $87,3 \%$ das que tinham estresse se encontravam em resistência, 2,95\% em alerta, 9,8\% em quase-exaustão e 2,95\% na fase de exaustão. Todos os meninos que apresentaram estresse encontravam-se na fase de resistência (Tabela 1).

Em relação à predominância de sintomas físicos e/ou psicológicos, os adolescentes avaliados apresentaram sintomas psicológicos em maior grau $(82,35 \%)$. Os que tinham mais sintomas físicos se constituíam em $12,6 \%$ e os que apresentaram ambos os sintomas com igual freqüência foram $5 \%$ dos participantes. 
Tabela 1- Características socioeconômicas e nutricionais, escores de estresse e imagem corporal dos adolescentes por sexo e estado nutricional. Ribeirão Preto, SP, 2008-2009.

\begin{tabular}{|c|c|c|c|c|c|c|}
\hline & \multicolumn{2}{|c|}{ Sexo } & \multicolumn{4}{|c|}{ Estado Nutricional } \\
\hline & Masculino & Feminino & Baixo Peso & Eutrófico & Sobrepeso & Obesidade \\
\hline Idade, $M(S D)$ & $16,14(1,10)$ & $15,72(1,01)$ & $17(0)$ & $15,7(1)$ & $16(1)$ & $15,7(0,9)$ \\
\hline \multicolumn{7}{|c|}{ Medida antropométrica, $M(S D)$} \\
\hline $\operatorname{IMC}\left(\mathrm{kg} / \mathrm{m}^{2}\right)$ & $22,06(5,42)$ & $21,67(4,67)$ & $15,6(0,7)$ & $21,2(3,5)$ & $26,56(1,3)$ & $43,1(8,9)$ \\
\hline \multicolumn{7}{|c|}{ Estado nutricional, $n(\%)$} \\
\hline Baixo Peso & $1(2,1)$ & $4(2,4)$ & - & - & - & - \\
\hline Eutrófico & $43(91,6)$ & $151(90,9)$ & - & - & - & - \\
\hline Sobrepeso & $2(4,2)$ & $8(4,9)$ & - & - & - & - \\
\hline Obesidade & $1(2,1)$ & $3(1,8)$ & - & - & - & - \\
\hline \multicolumn{7}{|c|}{ Nível socioeconômico, $n(\%)$} \\
\hline A1 & 0 & 0 & 0 & 0 & 0 & 0 \\
\hline $\mathrm{A} 2$ & $1(2,1)$ & 0 & 0 & $1(100)$ & 0 & 0 \\
\hline B1 & $8(17)$ & $15(9)$ & 0 & $21(91,4)$ & $1(4,3)$ & $1(4,3)$ \\
\hline $\mathrm{B} 2$ & $12(25,5)$ & $54(32,5)$ & $3(4,5)$ & $62(94)$ & 0 & $1(1,5)$ \\
\hline $\mathrm{C} 1$ & $18(38,4)$ & $58(35)$ & $1(1,4)$ & $70(92)$ & $4(5,2)$ & $1(1,4)$ \\
\hline $\mathrm{C} 2$ & $7(15)$ & $28(17)$ & 0 & $31(88,6)$ & $3(8,6)$ & $1(2,8)$ \\
\hline $\mathrm{D}$ & $1(2,1)$ & $11(6,5)$ & $1(8,4)$ & $9(75)$ & $2(16,6)$ & 0 \\
\hline $\mathrm{E}$ & 0 & 0 & 0 & 0 & 0 & 0 \\
\hline \multicolumn{7}{|l|}{ Estresse, $n(\%)$} \\
\hline Sim & $17(36,2)$ & $102(61,45)$ & $3(2,52)$ & $112(94,11)$ & $3(2,52)$ & $1(0,85)$ \\
\hline Não & $30(63,8)$ & $64(38,55)$ & $2(2,12)$ & $82(87,23)$ & $7(7,5)$ & $3(3,2)$ \\
\hline \multicolumn{7}{|c|}{ Fases do estresse, $n(\%)$} \\
\hline Alerta & 0 & $3(2,95)$ & 0 & $3(100)$ & 0 & 0 \\
\hline Resistência & $17(100)$ & $86(87,3)$ & $2(1,94)$ & $98(95,14)$ & $2(1,94)$ & $1(0,98)$ \\
\hline $\begin{array}{l}\text { Quase- } \\
\text { exaustão }\end{array}$ & 0 & $10(9,8)$ & $1(10)$ & $8(80)$ & $1(10)$ & 0 \\
\hline Exaustão & 0 & $3(2,95)$ & 0 & $3(100)$ & 0 & 0 \\
\hline \multicolumn{7}{|c|}{ Sintomas predominantes, $n(\%)$} \\
\hline Físico $(\mathrm{F})$ & $3(17,6)$ & $12(11,75)$ & 0 & $14(93,3)$ & $1(6,7)$ & 0 \\
\hline $\begin{array}{l}\text { Psicológico } \\
\text { (P) }\end{array}$ & $12(70,6)$ & $86(84,3)$ & $3(3)$ & $92(94)$ & $2(2)$ & $1(1)$ \\
\hline $\mathrm{F}$ e $\mathrm{P}$ & $2(11,8)$ & $4(3,95)$ & 0 & $6(100)$ & 0 & 0 \\
\hline \multicolumn{7}{|c|}{ Escala de Figuras de Silhuetas $\left(\mathrm{kg} / \mathrm{m}^{2}\right), M(S D)$} \\
\hline IMC Atual & $25,9(7)$ & $27,8(6,5)$ & $22(7,7)$ & $26,9(6,3)$ & $35,2(3,8)$ & $38,7(5,2)$ \\
\hline $\begin{array}{l}\text { IMC } \\
\text { Desejado }\end{array}$ & $25(3,5)$ & $25,1(4)$ & $24(2,2)$ & $24,8(3,8)$ & $27,2(3,8)$ & $31,2(4,3)$ \\
\hline $\begin{array}{l}\text { Inacurácia da } \\
\text { percepção } \\
\text { corporal }\end{array}$ & $3,8(4,2)$ & $6,2(4,8)$ & $6.3(7,7)$ & $5,7(4,5)$ & $8,6(3)$ & $-4,4(8)$ \\
\hline $\begin{array}{l}\text { Insatisfação } \\
\text { Corporal }\end{array}$ & $-0,9(6,3)$ & $-2,7(6,9)$ & $2(8,5)$ & $-2,07(6,7)$ & $-8(5)$ & $-7,5(6,4)$ \\
\hline
\end{tabular}




\subsection{COPING}

As médias em cada fator de coping estão apresentadas na Tabela 2, de acordo com as variáveis sexo, estresse, estado nutricional e imagem corporal. De todos os fatores de coping, o autocontrole teve a maior média em todas as variáveis (sexo, estresse, estado nutricional e imagem corporal), sendo que as adolescentes do sexo feminino usaram mais significativamente essa estratégia do que o sexo masculino $F(1,190)=4, p=0,04$. De maneira geral, os fatores de coping mais utilizados pelos adolescentes foram fuga e esquiva e reavaliação positiva na maioria das variáveis enquanto que as menos utilizadas foram confronto e suporte social. Os meninos usaram mais a estratégia de fuga e esquiva e as maiores médias no sexo feminino foram no coping autocontrole, fuga e esquiva e reavaliação positiva.

Em relação à variável estresse, nota-se que os adolescentes com sintomas de estresse utilizaram significativamente mais todos os fatores de coping quando comparados ao grupo sem estresse $(p<0,05)$. As estratégias com menores médias utilizadas pelos adolescentes com estresse foram confronto, afastamento e suporte social (Tabela 2).

$\mathrm{Na}$ divisão de acordo com o estado nutricional, o grupo classificado como obesidade apresentou mais médias altas nos fatores de coping de afastamento, autocontrole, aceitação de responsabilidade, fuga e esquiva, resolução de problemas e reavaliação positiva quando comparados aos demais grupos de estado nutricional. Por outro lado, o grupo com baixo peso utilizou em maior quantidade apenas a estratégia de autocontrole.

Em relação às variáveis de imagem corporal, elas foram separadas de acordo com o valor obtido da comparação entre as silhuetas. Por exemplo, o escore de insatisfação corporal foi calculado pela diferença entre a silhueta escolhida como ideal e atual. Esse escore pode ser positivo, negativo ou zero. Se positivo, significa que o indivíduo gostaria de ter um corpo maior. Se negativo, significa que o indivíduo gostaria de ter um corpo menor. E, por fim, se zero, significa satisfação corporal (a mesma silhueta para ideal e atual foi escolhida). Em relação ao escore de inacurácia da percepção corporal, ele foi calculado pela diferença entre a silhueta escolhida como atual e o IMC real do participante. Se positivo, o indivíduo vê seu corpo maior do que realmente é, e se negativo, o indivíduo vê seu corpo menor do que realmente é. 
Tabela 2 - Média dos fatores de coping por sexo, estresse, estado nutricional e imagem corporal. Ribeirão Preto, SP, 2008-2009.

\begin{tabular}{|c|c|c|c|c|c|c|c|c|c|c|c|c|c|}
\hline $\begin{array}{l}\text { Fatores de } \\
\text { Coping }\end{array}$ & \multicolumn{2}{|c|}{ Sexo } & \multicolumn{2}{|c|}{ Estresse } & \multicolumn{4}{|c|}{ Estado Nutricional } & \multicolumn{5}{|c|}{ Imagem Corporal } \\
\hline Confronto & 0,44 & 0,63 & $\underset{\mathrm{a}}{0,72}$ & 0,41 & 0,25 & 0,59 & 0,68 & 0,87 & 0,41 & 0,67 & 0,54 & 0,66 & 0,59 \\
\hline Autocontrole & $\underset{\mathrm{a}}{0,9}$ & $\underset{\mathrm{b}}{1,11}$ & $\underset{\mathrm{a}}{1,14}$ & 0,97 & 1 & 1,07 & 0,96 & 1,55 & 1,05 & 1,11 & 1 & 1,14 & 1,06 \\
\hline Suporte social & 0,66 & 0,85 & 0,96 & 0,59 & 0,46 & 0,82 & 0,73 & 0,87 & 0,68 & 0,88 & 0,74 & 0,92 & 0,8 \\
\hline $\begin{array}{l}\text { Resolução de } \\
\text { problemas }\end{array}$ & 0,91 & 0,86 & $1^{\mathrm{a}}$ & $\underset{\mathrm{b}}{0,68}$ & 0,94 & 0,87 & 0,63 & 1,25 & 0,81 & 0,88 & 0,88 & 1,08 & 0,85 \\
\hline $\begin{array}{l}\text { Reavaliação } \\
\text { positiva }\end{array}$ & 0,94 & 1,1 & $\frac{1,17}{a}$ & 0,92 & 0,75 & 1,06 & 1,13 & 1,47 & 1,09 & 1,12 & 0,95 & 0,94 & 1,08 \\
\hline
\end{tabular}

Nota. Médias com mesma letra não são significativamente diferentes em relação aos outros grupos ao nível de 5\% pelo teste de Duncan. ANOVA (p $<0,05$ ); M: masculino; F: feminino. 
Os adolescentes com insatisfação corporal negativa usaram significativamente mais a estratégia de aceitação de responsabilidade quando comparados aos grupos satisfação corporal e insatisfação corporal positiva $(p<0,05)$. Os adolescentes satisfeitos com o corpo utilizaram mais as estratégias de autocontrole e reavaliação positiva. No grupo de insatisfação negativa, os fatores de coping mais usados foram autocontrole, fuga e esquiva e reavaliação positiva, e no grupo com insatisfação positiva foi a estratégia de autocontrole. Os adolescentes com inacurácia da percepção corporal negativa utilizaram mais a estratégia de autocontrole e resolução de problemas enquanto que aqueles com inacurácia da percepção corporal positiva usaram mais autocontrole, fuga e esquiva e reavaliação positiva.

Em relação aos fatores de coping utilizados em uma situação de desconforto com o próprio corpo, todos os fatores apresentaram correlação positiva significativa dois a dois (Tabela 3), ou seja, um fator tende a aumentar em grandeza conforme o outro fator também aumenta. As correlações mais fortes mostradas foram entre resolução de problemas e aceitação de responsabilidade $(0,59)$, fuga e esquiva e aceitação de responsabilidade $(0,57)$, reavaliação positiva e aceitação de responsabilidade $(0,57)$, reavaliação positiva e suporte social $(0,55)$, reavaliação positiva e resolução de problemas $(0,53)$ e assim por diante.

Tabela 3 - Correlação múltipla dos fatores de coping. Ribeirão Preto, SP, 2008-2009.

\begin{tabular}{lllllllll}
\hline & CON & AFA & AUC & SSO & ARE & FES & RPB & RPT \\
\hline CON & 1 & & & & & & & \\
AFA & $0,25^{*}$ & 1 & & & & & & \\
AUC & $0,26^{*}$ & $0,52^{*}$ & 1 & & & & & \\
SSO & $0,44^{*}$ & $0,29^{*}$ & $0,28^{*}$ & 1 & & & & \\
ARE & $0,53^{*}$ & $0,39^{*}$ & $0,48^{*}$ & $0,51^{*}$ & 1 & & & \\
FES & $0,48^{*}$ & $0,33^{*}$ & $0,32^{*}$ & $0,34^{*}$ & $0,57^{*}$ & 1 & & \\
RPB & $0,33^{*}$ & $0,27^{*}$ & $0,35^{*}$ & $0,48^{*}$ & $0,59^{*}$ & $0,32^{*}$ & 1 & \\
RPT & $0,30^{*}$ & $0,52^{*}$ & $0,54^{*}$ & $0,55^{*}$ & $0,57^{*}$ & $0,37^{*}$ & $0,53^{*}$ & 1 \\
\hline
\end{tabular}

Nota. ${ }^{*}$ Correlação de Pearson ( $\left.<<0,05\right)$; CON: confronto; AFA: afastamento; AUC: autocontrole; SSO: suporte social; ARE: aceitação de responsabilidade; FES: fuga-esquiva; RPB: resolução de problemas; RPT: reavaliação positiva. 


\subsection{IMAGEM CORPORAL}

Na Escala de Figuras de Silhuetas, a escolha do IMC Atual foi em média 27,8 \pm 6,5 $\mathrm{kg} / \mathrm{m}^{2}$ nas meninas e $25,9 \pm 7 \mathrm{~kg} / \mathrm{m}^{2}$ nos meninos (Tabela 1 ). No caso do IMC Desejado, a média foi de $25,10 \pm 4 \mathrm{~kg} / \mathrm{m}^{2}$ no sexo feminino e $25,05 \pm 3,5 \mathrm{~kg} / \mathrm{m}^{2}$ no sexo masculino. Comparando esses dados com as médias de IMC Real dos participantes, obtém-se a média de inacurácia da percepção corporal (Figura 2) em ambos os sexos: $6,2 \mathrm{~kg} / \mathrm{m}^{2}$ (meninas) e 3,8 $\mathrm{kg} / \mathrm{m}^{2}$ (meninos). A média de insatisfação (IMC médio Desejado - IMC médio Atual) foi -2,7 $\mathrm{kg} / \mathrm{m}^{2}$ no sexo feminino e $-0,9 \mathrm{~kg} / \mathrm{m}^{2}$ no sexo masculino (Figura 2).
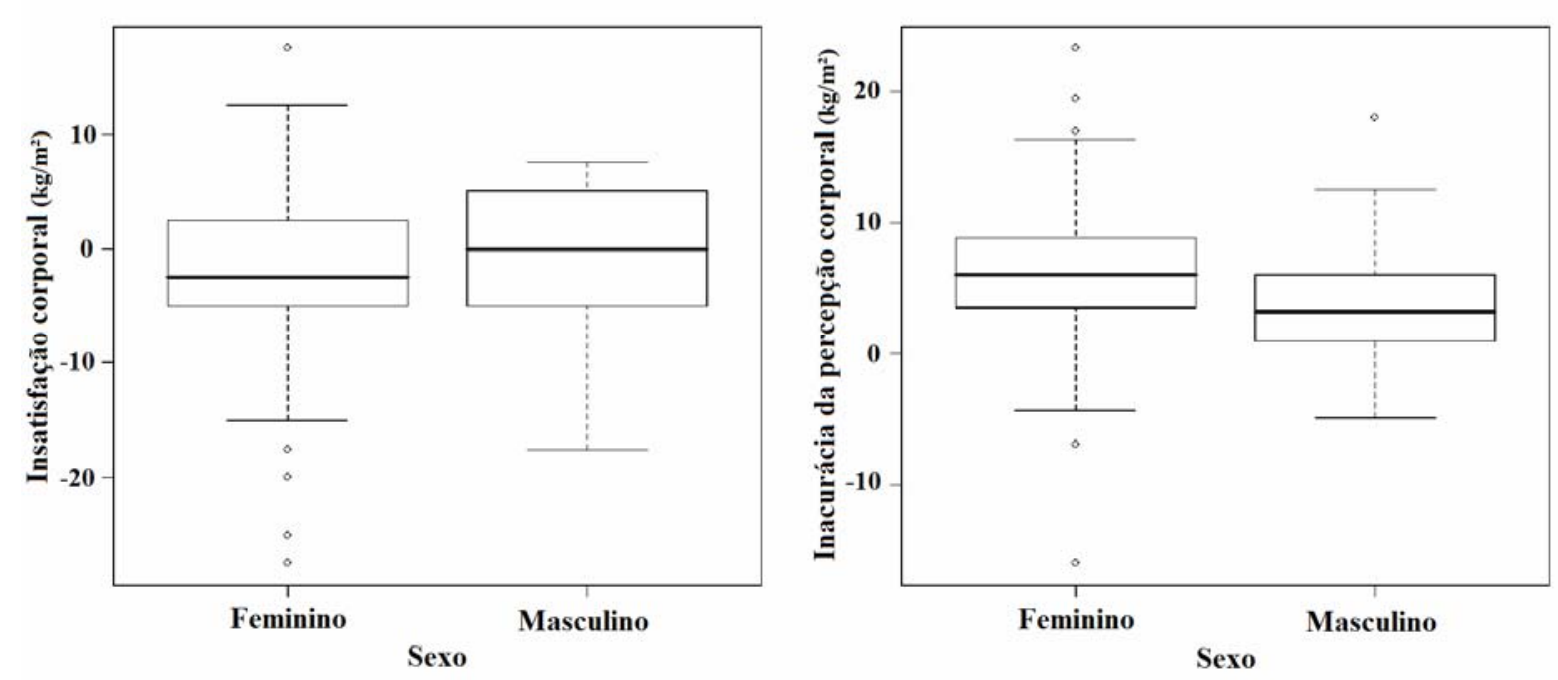

Figura 2 - Box-Plot dos escores de insatisfação e inacurácia da percepção corporal $\left(\mathrm{kg} / \mathrm{m}^{2}\right)$ nos adolescentes de acordo com o sexo. Ribeirão Preto, SP, 2008-2009.

Quando comparadas as médias de inacurácia segundo o sexo, as meninas apresentaram significativamente uma maior inacurácia da percepção corporal do que os meninos, $F(1,212)$ $=8,73, p=0,003$. Não houve diferença estatística significativa entre os sexos em relação à insatisfação corporal, $F(1,212)=2,75, p=0,099$.

A insatisfação e a inacurácia da percepção corporal estão caracterizadas na Figura 3 de acordo com o estado nutricional. Observa-se que a insatisfação no grupo com Baixo Peso foi positiva $\left(M=2 \pm 8,5 \mathrm{~kg} / \mathrm{m}^{2}\right)$, ou seja, eles desejavam ter uma dimensão corporal maior. Os demais grupos desejavam reduzir o tamanho da silhueta: Eutrófico $\left(M=-2,07 \pm 6,7 \mathrm{~kg} / \mathrm{m}^{2}\right)$, 
Sobrepeso $\left(M=-8 \pm 5 \mathrm{~kg} / \mathrm{m}^{2}\right)$ e Obesidade $\left(M=-7,5 \pm 6,4 \mathrm{~kg} / \mathrm{m}^{2}\right)$. Não houve diferença significativa entre esses grupos.

No entanto, diferenças estatísticas foram encontradas entre os grupos nutricionais em relação à inacurácia da percepção corporal, $F(3,212)=7,85, p<0,001$. Nota-se que os grupos Baixo Peso $\left(M=6,3 \pm 7,7 \mathrm{~kg} / \mathrm{m}^{2}\right)$, Eutrófico $\left(M=5,7 \pm 4,5 \mathrm{~kg} / \mathrm{m}^{2}\right)$ e Sobrepeso $(M=$ $8,6 \pm 3 \mathrm{~kg} / \mathrm{m}^{2}$ ) se vêem maior do que realmente são (inacurácia da percepção corporal positiva). Os adolescentes com Sobrepeso apresentaram uma inacurácia significativamente maior do que os Eutróficos. O único grupo com inacurácia da percepção corporal negativa foram os adolescentes com Obesidade $\left(M=-4,4 \pm 8 \mathrm{~kg} / \mathrm{m}^{2}\right)$. Esse grupo diferiu significativamente dos demais.
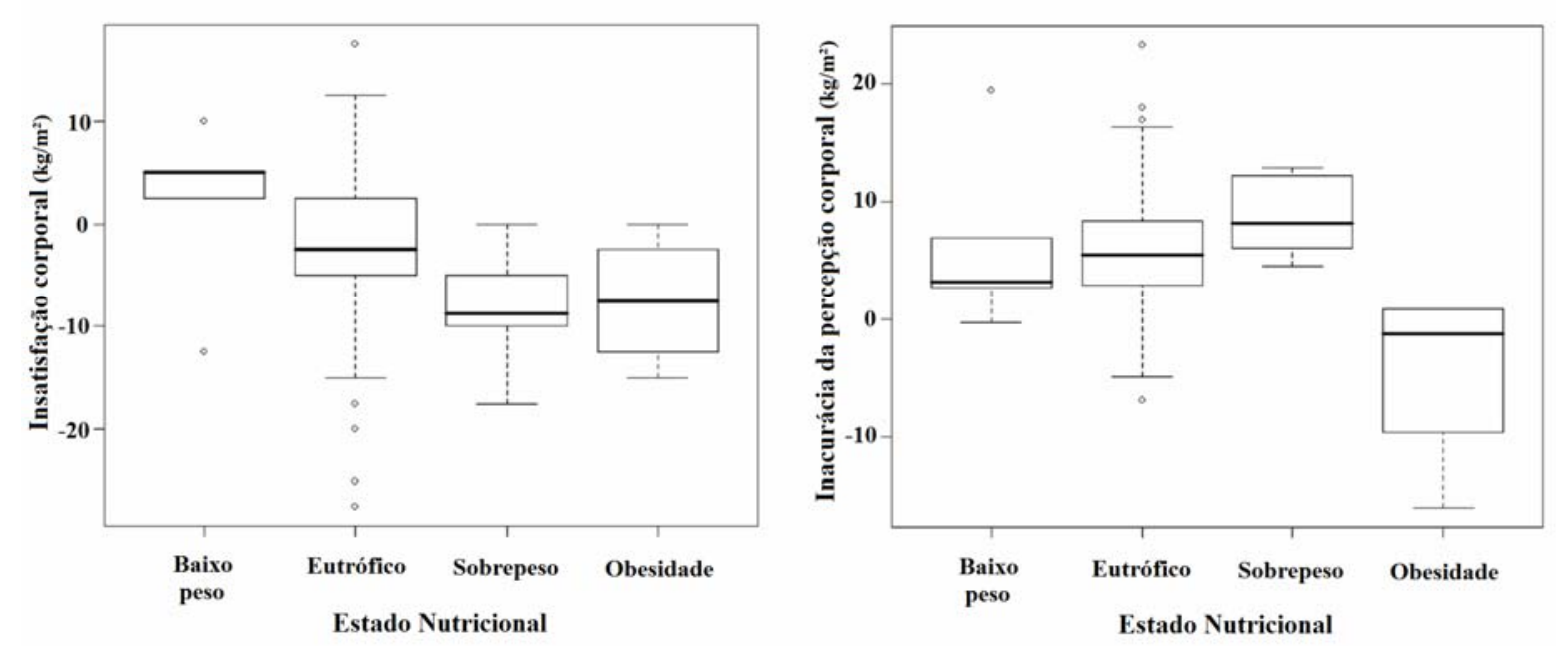

Figura 3 - Box-Plot dos escores de insatisfação e inacurácia da percepção corporal $\left(\mathrm{kg} / \mathrm{m}^{2}\right)$ nos adolescentes de acordo com o estado nutricional. Ribeirão Preto, SP, 2008-2009.

Uma correlação estatisticamente significativa, negativa, de moderada a forte foi encontrada entre insatisfação e inacurácia da percepção corporal $(r=-0,65)$. Esse resultado sugere que quanto mais negativa a insatisfação, mais positiva é a inacurácia e vice-versa.

Por fim, observa-se na Figura 4 que a porcentagem dos adolescentes que estão satisfeitos com o próprio corpo é baixa: $15,6 \%$ as meninas e $27,6 \%$ os meninos. A maioria das meninas está insatisfeita negativamente $(57,8 \%)$ e dos meninos insatisfeitos positivamente $(38,3 \%)$. Ambos os sexos apresentam uma grande inacurácia da percepção corporal positiva ( $91,5 \%$ meninas e $72,3 \%$ meninos). 


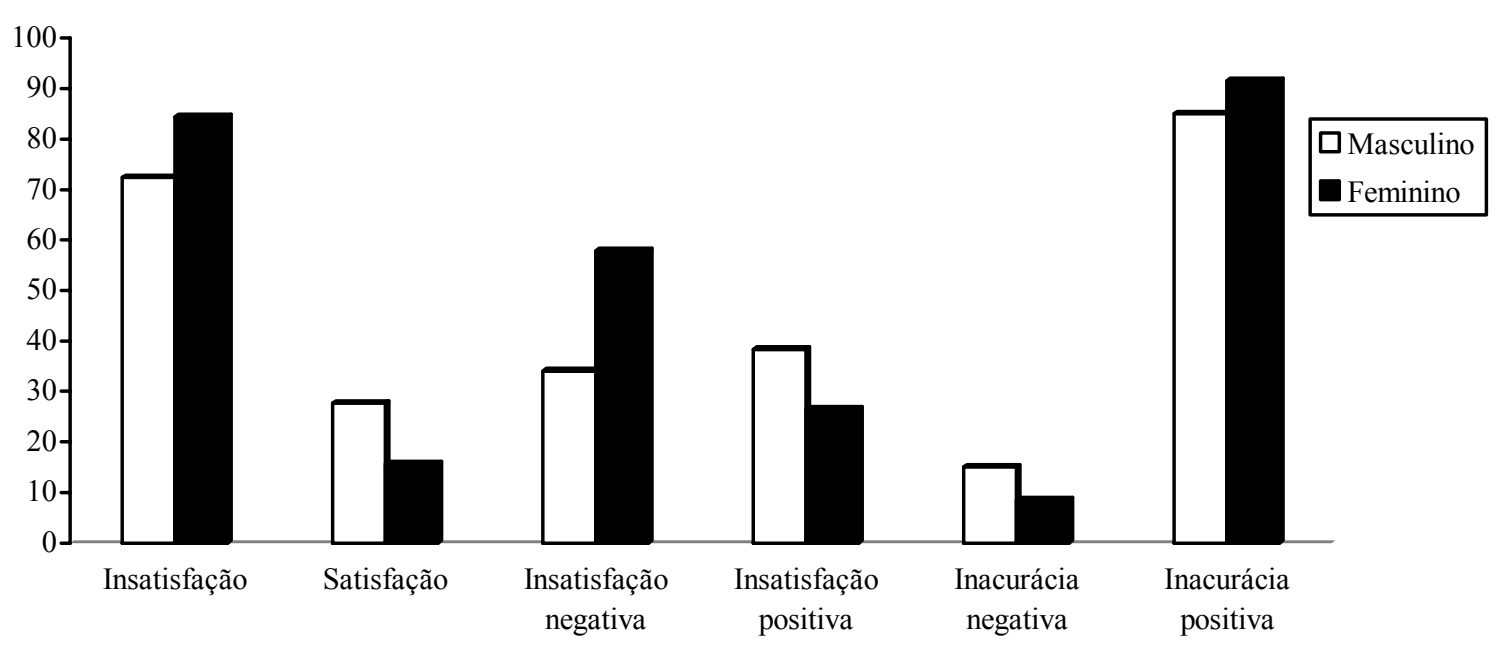

Figura 4 - Distribuição dos adolescentes com insatisfação, satisfação corporal e inacurácia da percepção corporal de acordo o sexo. Ribeirão Preto, SP, 2008-2009.

\subsection{ASSOCIAÇÕES ENTRE AS VARIÁVEIS DO ESTUDO}

Mediante o Teste Exato de Fisher que comparou os fatores de coping por sexo, estado nutricional e estresse, os resultados obtidos mostraram que houve associação significativa entre os fatores confronto, afastamento, suporte social, aceitação de responsabilidade, fuga e esquiva com os sintomas de estresse $(p<0,05)$. Não há evidências de associação entre os fatores de coping de autocontrole, resolução de problemas e reavaliação positiva com as variáveis em questão.

O Teste Exato de Fisher também mostrou evidências de que a insatisfação esteja associada com o sexo, percentil e estresse $(p<0,05)$. Observa-se que, dos participantes analisados, 58,64\% do sexo feminino, 90\% daqueles com sobrepeso, 75\% dos com obesidade, $51 \%$ dos que estão classificados como eutróficos e 58,62\% dos com estresse têm insatisfação negativa. Nota-se que, daqueles classificados como baixo peso, $80 \%$ apresentam insatisfação positiva. Outra associação ocorrida foi entre inacurácia da percepção corporal e estado nutricional $(p<0,05)$. A maioria dos grupos do estado nutricional está associada com a inacurácia da percepção corporal positiva: $100 \%$ dos adolescentes com sobrepeso, 90,72\% dos eutróficos e $80 \%$ com baixo peso.

Por meio da Análise de Regressão Logística, os resultados obtidos mostraram que os adolescentes com estresse têm 3,14 vezes a razão de chance de utilizarem os fatores 
confronto, 2,09 afastamento, 2,06 autocontrole, 3,33 suporte social, 4,40 aceitação de responsabilidade e 3,17 fuga e esquiva. Além disso, o fator autocontrole também foi influenciado pelo sexo feminino $(\mathrm{OR}=2,27)$. No fator de fuga e esquiva, o estado nutricional Sobrepeso/Obesidade exerce uma influência maior $(\mathrm{OR}=4,99)$ que o estresse $(\mathrm{OR}=3,17)$ na utilização dessa estratégia. Por fim, os adolescentes com insatisfação negativa também apresentaram uma chance 2,34 vezes maior de utilizarem a estratégia de aceitação de responsabilidade. Nenhuma das variáveis em estudo (sexo, estado nutricional, estresse, imagem corporal) influenciou os fatores resolução de problemas e reavaliação positiva.

Por meio da ANOVA verificou-se que o grupo com insatisfação negativa utilizou significativamente mais o fator de aceitação de responsabilidade quando comparado com os grupos satisfação e insatisfação positiva $(p<0,05)$. Além disso, não houve diferença significativa na comparação das variáveis inacurácia da percepção corporal, $F(1,212)=0,86$, $p=0,355$, e insatisfação corporal, $F(1,212)=1,43, p=0,233$, em relação à presença ou ausência dos sintomas de estresse $(p>0,05)$. 


\section{DISCUSSÃO}

Os adolescentes da presente pesquisa apresentaram sintomas de estresse, predominantemente na fase de resistência e com sintomas psicológicos em maior grau. Observou-se também que os adolescentes com sintomas de estresse utilizaram significativamente mais todos os fatores de coping quando comparados ao grupo sem estresse. A estratégia de enfrentamento mais usada em uma situação estressante envolvendo desconforto com o corpo foi o autocontrole. Além dessa estratégia, os adolescentes também usaram as estratégias fuga e esquiva e reavaliação positiva. As estratégias menos utilizadas foram confronto, afastamento e busca por apoio social. Nota-se que os adolescentes insatisfeitos com o corpo negativamente (ou seja, que desejavam um corpo menor) tiveram uma maior probabilidade de usarem a estratégia de aceitação de responsabilidade e aqueles com sobrepeso/obesidade de usarem mais a estratégia de fuga e esquiva.

Uma situação estressante envolvendo desconforto com o corpo pode ser vista como controlável para alguns e como incontrolável para outros. No presente estudo nota-se que as estratégias de enfrentamento apontadas acima usadas pelos adolescentes foram predominantemente estratégias centradas na emoção. A partir desse resultado pode-se sugerir que provavelmente os adolescentes avaliaram a situação como um evento incontrolável. Zakir (2003) coloca que a avaliação da situação como controlável ou incontrolável tem implicações na seleção das respostas de coping, pois, se o indivíduo se percebe incapaz de agir sobre o estressor, provavelmente lançará mão de estratégias compatíveis com sua incapacidade. Estas estratégias seriam, no caso, inclusas no coping centrado na emoção, enquanto o coping centrado no problema teria a preferência dos indivíduos que se percebem capazes de razoável grau de controle sobre os eventos.

De acordo com Folkman e Lazarus (1985), a característica de uma situação estressante e a avaliação do indivíduo de que é amena para o controle pessoal são fatores importantes para a preferência do coping centrado no problema ao invés do coping centrado na emoção. Lazarus e Folkman (1984) afirmam que o as estratégias centradas no problema são usadas mais frequentemente para situações controláveis, e as estratégias centradas na emoção são geralmente empregadas em situações incontroláveis. Tem sido amplamente reconhecido dentro da literatura de estresse e coping que o constructo de controle pessoal frente ao estresse tem efeitos poderosos na maneira pela qual o indivíduo enfrenta o estresse (ENDLER et al., 2000). 
Estudos que investigaram a avaliação de controlabilidade dos eventos encontram que quando um evento estressante foi avaliado como controlável, as estratégias de enfrentamento centradas no problema revelaram mais consequências positivas, enquanto que quando o evento estressante era percebido como incontrolável, as estratégias de enfrentamento centrados no problema levaram a consequências negativas (FORSYTHE; COMPAS, 1987; VITALIANO et al., 1990).

Além disso, é importante notar que alguns autores encontraram associações entre o coping centrado na emoção e desordens alimentares (FRYER; WALLER; KROESE, 1997; MAYHEW; EDELMANN, 1989). Koff e Sangani (1997), no estudo com jovens universitários, mostram que o estresse resultante de uma imagem corporal negativa quando combinada com o uso de estratégias de enfrentamento centradas na emoção, levavam a distúrbios no comportamento alimentar. Resultados de outros estudos recentes levaram a conclusões semelhantes. Yang, Kim e Yoon (2010) e García-Grau et al. (2002), apontam que estratégias passivas (pensamento positivo e evitação) e reações emocionais mal adaptadas aos problemas estavam associadas a transtornos alimentares. Por conseguinte, o coping focado na emoção utilizado pelos adolescentes na presente pesquisa pode vir a favorecer um manejo insatisfatório das situações estressantes envolvidas com o próprio corpo e, consequentemente, levar a uma maior insatisfação e inacurácia da percepção corporal. Claramente, essa afirmação necessita ser mais explorada em futuros estudos.

Em relação à imagem corporal no presente estudo, destaca-se que a maioria dos adolescentes estavam insatisfeitos com o corpo negativamente (ou seja, que gostariam de ter uma silhueta menor) e apresentavam inacurácia da percepção corporal positiva (viam a si próprios maiores que a realidade), principalmente o sexo feminino. Essas duas variáveis estavam correlacionadas negativamente: quanto mais negativa a insatisfação corporal, mais positiva é a inacurácia da percepção corporal, ou essa relação ao contrário. Portanto, os adolescentes que se viam maiores de que seus tamanhos reais desejam uma silhueta menor, enquanto aqueles que se viam mais magros gostariam de aumentar a silhueta.

Esses resultados são consistentes com estudos anteriores que mostraram que ambos os gêneros superestimaram o tamanho corporal (LAUS, 2009; McCABE et al., 2006) e estavam insatisfeitos com o corpo (LAUS, 2009; KAGAWA et al., 2007; SABBAH et al. 2009). A forma de superestimação talvez seja diferente entre os gêneros. McCabe et al. (2006) sugeriu que o sexo feminino talvez superestime seu tamanho porque elas acreditam que estão mais gordas do que realmente são, e o sexo masculino superestima seu tamanho porque eles se percebem como mais "musculosos" do que de fato são. Esses autores também propuseram 
que, uma forma de clarificar o quanto isso ocorre ou não seria acrescentar uma questão se o corpo deveria ser "mais gordo", "mais magro" ou "mais musculoso".

Um dos fatores que muitos autores apontam contribuir para a inacurácia da percepção corporal e insatisfação corporal é a ênfase dada pela sociedade do valor da magreza para as mulheres (WISEMAN et al., 1992) e a muscularidade para os homens (PETRIE et al., 2006) nas últimas décadas. De acordo com Neighbors et al. (2008) esses ideais sociais modelam as avaliações e interpretações do corpo no nível individual. As normas culturais e os ideais de magreza/muscularidade são incorporados e frequentemente transmitidos por representações na mídia, modelos públicos e discursos culturais.

Kronenfeld, Reba-Harrelson, Holle, Reyes e Bulik (2010) destacam que é plausível que uma percepção do próprio corpo favorável serve como um fator protetivo contra o engajamento em dietas não saudáveis e práticas de controle de peso que possam contribuir para desordens alimentares. Vários estudos mostram um grande número de consequências para saúde devido ao aumento da possibilidade do estabelecimento de comportamentos não saudáveis em busca de um ideal corporal que geralmente é incompatível com a biologia humana. Neumark-Sztainer et al. (2006), por exemplo, apresentam dados que mostram que baixos níveis de satisfação corporal estão associados com mais comportamentos de risco para a saúde, tais como métodos inadequados de controle de peso, compulsão alimentar e poucos comportamentos de promoção de saúde, como, por exemplo, a realização de atividade física.

A relação entre estresse e imagem corporal foi apontada na presente pesquisa por meio do Teste Exato de Fisher, o qual mostrou evidências de que a insatisfação corporal esteja associada com o sexo feminino, com os estados nutricionais de eutrofia, sobrepeso, obesidade e estresse. No entanto, é necessário cautela para a interpretação desse resultado, visto que não houve associação entre estresse e imagem corporal por meio da ANOVA. Portanto, é necessária uma investigação mais detalhada da relação entre essas variáveis visto que no presente estudo somente foi avaliado a presença ou ausência de estresse e não houve uma avaliação mais ampla para saber por quais situações estressantes específicas os adolescentes estavam de fato passando. Segundo alguns autores (CAUSEY; DUBOW, 1992; COMPAS; MALCARNE; FONDARO, 1988) o estudo de estressores específicos é considerado uma mais valia, tendo em conta que os fatores do meio, as variáveis pessoais, em especial as avaliações de ameaça e controle sobre o estressor, ou as exigências da situação estressante poderão influenciar o uso de diferentes estratégias para estressores distintos (LAZARUS; FOLKMAN, 1984). 
Por fim, avaliando o estado nutricional dos adolescentes desse estudo, destaca-se que a maior porcentagem em ambos os sexos foi classificada como eutrófica. Esse dado contrasta com grande parte da literatura, que aponta para uma prevalência de excesso de peso em todas as faixas etárias nos países em desenvolvimento (DE ONIS; BLÖSSNER, 2000; MENDEZ; MONTEIRO; POPKIN, 2005). A comparação de dois estudos representativos da população de adolescentes brasileiros - Estudo Nacional de Despesa Familiar (Endef), realizado em 1974-1975, e Pesquisa sobre Padrões de Vida (PPV), de 1996-1997 - mostra que, em apenas duas décadas, o excesso de peso mais do que triplicou entre os meninos (de 2,6\% para 11,8\%) e é mais do que o dobro entre as meninas (de 5,8\% para 15,3\%) (VEIGA; CUNHA; SICHIERI, 2004). Dados mais recentes, obtidos a partir da Pesquisa Nacional de Orçamentos Familiares (POF), conduzida em 2002-2003, mostram que o excesso de peso já atinge 17,9\% e $15,4 \%$ dos adolescentes brasileiros de sexo masculino e feminino, respectivamente (IBGE, 2006).

Cintra et al. (2007) mostraram que adolescentes de São Paulo, de 10 a 15 anos de idade, vêm apresentando um importante aumento nos valores de IMC nos diferentes percentis, indicando que, com o passar dos anos, há uma tendência cada vez maior ao ganho de peso corporal, principalmente entre o sexo masculino.

O estudo de Araújo et al. (2010) avaliou a situação nutricional dos adolescentes do $9^{\circ}$ ano do ensino fundamental de escolas públicas e privadas de todas as capitais brasileiras. A média de idade dos 60.973 participantes da pesquisa foi de 14,2 anos e 79,2\% dos adolescentes freqüentavam escolas públicas. Segundo os autores, as disparidades na situação nutricional dos adolescentes foram marcantes entre as cinco macrorregiões do país. $\mathrm{O}$ percentual de adolescentes com déficit de altura foi três vezes maior na região Norte $(5,5 \%)$ do que no Sul $(1,8 \%)$ do Brasil. Já as maiores taxas de excesso de peso e obesidade foram encontradas entre os jovens das regiões Sul e Sudeste. Além disso, observou-se que os adolescentes que frequentavam escolas da rede pública apresentaram as maiores prevalências de déficit de altura $(3,3 \%)$ e de peso $(3,1 \%)$. Por sua vez, os escolares da rede privada mostraram prevalências mais elevadas de excesso de peso e de obesidade $(31,0 \%$ e $10,0 \%)$ do que seus pares da rede pública. Nesse sentido, Araújo et al. (2010) destacam uma nítida tendência de prevalências de déficits mais elevadas entre as categorias caracterizadas como de status socioeconômico mais baixo (escolas públicas, baixa escolaridade da mãe e regiões Norte, Nordeste). Contrariamente, as prevalências mais elevadas de excesso de peso e obesidade encontram-se entre os adolescentes das escolas privadas, filhos de mães com maior nível de escolaridade e residentes nas regiões Sul e Sudeste do país (ARAÚJO et al., 2010). 
Considerando esse dado, talvez a predominância de eutrofia nos adolescentes do presente estudo seja em decorrência de pertenceram a um status econômico mais baixo e serem de escolas públicas. Mais índices de sobrepeso e obesidade talvez seriam encontrados se a amostra tivesse adolescentes provenientes de escolas privadas, com status socioeconômico mais elevado. No entanto, ressalta-se que a predominância de eutrofia pode ser um dado positivo visto que a predominância de sobrepeso e obesidade na adolescência tem sido relacionada cada vez mais ao sedentarismo e à adoção de práticas alimentares inadequadas, caracterizadas por dietas ricas em gorduras, açúcares, sódio e com baixo consumo de frutas e hortaliças (SAMUELSON, 2000; NEUTZLING et al., 2007). Um maior aprofundamento é necessário para saber se esses adolescentes eutróficos realmente estão saudáveis, por meio de investigações dos hábitos alimentares, da realização de atividades físicas, influências familiares e talvez a adoção de outras medidas mais refinadas de avaliação do perfil lipídico. Como pontuam Araújo et al. (2010): "a adolescência oferece oportunidade única para se buscar a realização de uma transição nutricional saudável entre a infância e a vida adulta." 
CONCLUSÕES 


\section{CONCLUSÕES}

Pode-se concluir que, no presente estudo, os adolescentes:

$\checkmark$ Estavam em sua maioria no estado nutricional de eutrofia.

$\checkmark$ Apresentaram sintomas de estresse e estavam na fase de resistência, com sintomas psicológicos predominantes.

$\checkmark$ Utilizaram estratégias de enfrentamento centradas na emoção para lidarem com uma situação estressante que envolvia desconforto com o corpo.

$\checkmark$ Estressados utilizaram mais estratégias de enfrentamento para lidarem com a situação estressante do que aqueles sem estresse.

$\checkmark$ Ambos os sexos estavam insatisfeitos com o corpo e superestimaram seu tamanho corporal. 


\section{REFERÊNCIAS ${ }^{2}$}

ADAMI, F. et al. Insatisfação corporal e atividade física em adolescentes da região continental de Florianópolis. Psicologia: Teoria e Pesquisa, v. 24, n. 2, p. 143-149, 2008.

ALMEIDA, D. M.; KESSLER, R. C. Everyday stressors and gender differences in daily distress. Journal of Personality and Social Psychology, v. 75, n. 3, p. 670-680, 1998.

ALMEIDA, G. A. N.; LOUREIRO, S. R.; SANTOS, J. E. A imagem corporal de mulheres morbidamente obesas avaliadas através do desenho da figura humana. Psicologia: Reflexão e Crítica, v. 15, n. 2, p. 283-292, 2002.

ALTSHULER, J. L.; RUBLE, D. N. Developmental changes in children's awareness of strategies for coping with uncontrollable stress. Child Development, v. 60, p. 1337-1349, 1989.

ALVARENGA, M. S. et al. Insatisfação com a imagem corporal em universitárias brasileiras. Jornal Brasileiro de Psiquiatria, v. 59, n. 1, p. 44-51, 2010.

ANDERSEN, L. F. et al. Dietary intake among Norwegian adolescents. European Journal of Clinical Nutrition, v. 49, n. 8, p. 555-564, 1995.

ARAÚJO, C. et al. Estado nutricional dos adolescentes e sua relação com variáveis sociodemográficas: pesquisa nacional de saúde do escolar (PeNSE), 2009. Ciência e Saúde Coletiva, v. 15, p. 3077-3084, 2010.

ARNETT, J. J. Adolescent storm and stress reconsidered. American Psychologist, v. 54, p. 317-326, 1999.

BAIGRIE, S. S.; GIRÁLDEZ, S. L. Examining the relationship between binge eating and coping strategies and the definition of binge eating in a sample of Spanish adolescents. The Spanish Journal of Psychology, v. 11, n. 1, p. 172-180, 2008.

BANFIELD, S. S.; McCABE, M. P. An evaluation of the construct of body image. Adolescence, v. 37, n. 146, p. 373-393, 2002.

\footnotetext{
${ }^{2}$ De acordo com a Associação Brasileira de Normas Técnicas. NBR 6023.
} 
BARKER, E. T.; GALAMBOS, N. L. Body dissatisfaction of adolescent girls and boys: Risk and resource factors. Journal of Early Adolescence, v. 23, p. 141-165, 2003.

BARKER, M. E.; THOMPSON, K. A.; McCLEAN, S. I. Attitudinal dimensions of food choice and nutrient intake. British Journal of Nutrition, v. 74, p. 649-659, 1995.

BARLETT, C. P.; VOWELS, C. L.; SAUCIER, D. A. Meta-analyses of the effects of media images on men's body image concerns. Journal of Social and Clinical Psychology, v. 27, p. 279-310, 2008.

BARNETT, R. C.; BIENER, L.; BARUCH, G. K. Gender \& stress. New York: The Free Press, 1987.

BENEDIKT, R.; WERTHEIN, E. H.; LOVE, A. Eating attitudes and weight-loss attempts in female adolescents and their mothers. Journal of Youth Adolescence, v. 27, n. 1, p. 43-57, 1998.

BENNETT, D. A.; COOPER, C. L. Eating disturbance as a manifestation of the stress process: A review of the literature. Stress Medicine, v. 15, p. 167-182, 1999.

BOEKAERTS, M. Coping with stress in childhood and adolescence. IN: M. ZEIDNER; N. S. ENDLER (Eds.), Handbook of Coping (p. 452-484). New York, NY: Wiley, 1996.

BOGT, T. F. M. et al. Body Mass Index and body weight perception as risk factors for internalizing and externalizing problem behavior among adolescents. Journal of Adolescent Health, v. 39, p. 27-34, 2006.

BOWKER, A. et al. Coping with daily hassles in the peer group in early adolescence: Variations as a function of peer experience. Journal of Research on Adolescence, v. 10, p. 211-243, 2000.

BRANCO, L. M.; HILÁRIO, M. O. E.; CINTRA, I. P. Percepção e satisfação corporal em adolescentes e a relação com seu estado nutricional. Revista de Psiquiatria Clínica, v. 33, n. 6, p. 292-296, 2006.

BRASIL. Ministério da Saúde. Estatuto da criança e do adolescente. Brasília, DF: 2008. Disponível em: http://bvsms.saude.gov.br/bvs/publicacoes/ estatuto_crianca_adolescente_ 3ed.pdf 
BREINBAUER, C.; MADDALENO, M. Teorias de estresse e enfrentamento. In:

Jovens: escolhas e mudanças - promovendo comportamentos saudáveis em adolescentes. São Paulo: Roca, 2008. cap. 20.

BRUCH, H. Perceptual and conceptual disturbances. Psychological Medicine, v. 24, p. 187194, 1962.

BYRNE, D. G.; DAVENPORT, S. C.; MAZANOV, J. Profiles of adolescent stress: The development of the adolescent stress questionnaire (ASQ). Journal of Adolescence, v. 30, p. 393-416, 2007.

CAFRI, G. et al. Pursuit of the muscular ideal: Physical and psychological consequences and putative risk factors. Clinical Psychology Review, v. 25, p. 215-239, 2005.

CAHILL, S.; MUSSAP, A. J. Emotional reactions following exposure to idealized bodies predict unhealthy body change attitudes and behaviors in women and men. Journal of Psychosomatic Research, v. 62, n. 6, p. 631-639, 2007.

CALAIS, S. L.; ANDRADE, L. M. B.; LIPP, M. E. N. Diferenças de sexo e escolaridade na manifestação de stress em adultos jovens. Psicologia: Reflexão e Crítica, v. 16, n. 2, p. 257 263, 2003.

CAMPANA, A. N. N. B.; TAVARES, M. C. G. C. F. Avaliação da imagem corporal: instrumentos e diretrizes para pesquisa. São Paulo: Phorte, 2009.

CAMPAYO, M. A. et al. Spanish version of the Gardner body image validation scale in patients with eating behavior disorders. Actas Espanolas de Psiquiatria, v. 31, p. 59-64, 2003.

CARTWRIGHT, M. et al. Stress and dietary practices in adolescents. Health Psychology, v. 22, p. 362-369, 2003.

CASH, T. Body image: Past, present, and future. Body Image, v. 1, n. 1, p. 1-5, 2004.

CASH, T. F.; DEAGLE, E. A. The nature and extent of body image disturbances in anorexia nervosa: A meta-analysis, International Journal of Eating Disorders, v. 22, p. 107-125, 1997. 
CAUSEY, D.; DUBOW, E. Development of a self-report measure for elementary school children. Journal of Clinical Child Psychology, v. 21, n. 1, p. 47-59, 1992.

CCEB, Critério Padrão de Classificação Econômica Brasil: O novo critério padrão de classificação econômica Brasil, 2008. Disponível em: <http://www.abep.org/codigosguias/ Criterio_Brasil_2008.pdf>. Acesso em: 10 nov. 2007.

CINTRA, I. P. et al. Evolução em duas séries históricas do índice de massa corporal em adolescentes. Jornal de Pediatria, v. 83, n. 2, p. 157-162, 2007.

COHANE, G. H.; POPE, H. G. Body image in boys: A review of the literature. International Journal of Eating Disorders, v. 29, p. 373-379, 2001.

COMPAS, B. E. et al. Coping with stress during childhood and adolescence: Problems, progress, and potential in theory and research. Psychological Bulletin, v. 12, p. 87-127, 2001.

COMPAS, B.; MALCARNE, V.; FONDACARO, K. Coping with stressful events in older children and young adolescents. Journal of Consulting and Clinical Research, n. 56 n. 3, p. 405- 411, 1988.

CONTI, M. A. Imagem corporal e estado nutricional de estudantes de uma escola particular. 2002. 78 f. Dissertação (Mestrado em Nutrição) - Faculdade de Saúde Pública, Universidade de São Paulo, São Paulo, 2002.

CONTI, M. A. Os aspectos que compõem o conceito de imagem corporal pela ótica do adolescente. Revista Brasileira de Crescimento e Desenvolvimento Humano, v. 18, n. 3, p. 240-253, 2008.

CONTI, M. A.; LATORRE, M. R. D. O. Estudo de validação e reprodutibilidade de uma escala de silhueta para adolescentes. Psicologia em Estudo, v. 14, n. 4, p. 699-706, 2009.

COQUEIRO, R. S. et al. Insatisfação com a imagem corporal: avaliação comparativa da associação com o estado nutricional em universitários. Revista de Psiquiatria do Rio Grande do Sul, v. 30, n. 1, p. 31-38, 2008.

CORDÁS, T. A.; CASTILHO, S. Imagem corporal nos transtornos alimentares instrumentos de avaliação: "Body Shape Questionnaire". Psiquiatria Biológica, v. 2, n. 1, p. 17-21, 1994. 
DAVE, D.; RASHAD, I. Overweight status, self-perception, and suicidal behaviors among adolescents. Social Science \& Medicine, v. 68, n. 9, p. 1685-1691, 2009.

DAVIS, M. C.; BURLESON, M. H.; KRUSZEWSKI, D. M. Gender: Its relationship to stressor exposure, cognitive appraisal/coping processes, stress responses, and health outcomes. In: CONTRADA, R. J.; BAUM, A. The handbook of stress science: Biology, psychology, and health. New York: Springer Publishing Company, 2011. cap. 19, p. 247-261.

DE ONIS, M.; BLÖSSNER, M. Prevalence and trends of overweight among preschool children in developing countries. The American Journal of Clinical Nutrition, v. 72, p. 1032-1039, 2000.

DE ONIS, M. et al. Development of a WHO growth reference for school-aged children and adolescents. Bulletin of the World Health Organization, v. 85, p. 660-667, 2007.

DITTMAR, H. How do "Body Perfect" ideals in the media have a negative impact on body image and behaviors? Factors and processes related to self and identity. Journal of Social and Clinical Psychology, v. 28, n.1, p. 1-8, 2009.

DOHNT, H. K.; TIGGEMANN, M. Body image concerns in young girls: The role of peers and media prior to adolescence. Journal of Youth and Adolescence, v. 35, n. 2, p. 141-151, 2006.

DUNKLEY, T. L.; WERTHEIM, E. H.; PAXTON, S. J. Examination of a model of multiple sociocultural influences on adolescent girls' body dissatisfaction and dietary restraint. Adolescence, v. 36, p. 265-279, 2001.

DURKIN, S. J.; PAXTON, S. J. Predictors of vulnerability to reduced body image satisfaction and psychological wellbeing in response to exposure to idealized female media images in adolescent girls. Journal of Psychosomatic Research, v. 56, p. 995-1005, 2002.

EBATA, A. T.; MOOS, R. H. Personal, situational, and contextual correlates of coping in adolescence. Journal of Research on Adolescence, v. 4, p. 99-125, 1994.

EBATA, A. T.; MOOS, R. H. Coping and adjustment in distressed and healthy adolescents. Journal of Applied Developmental Psychology, v. 12, n. 1, p. 33-54, 1991.

EISENBERG, M. E.; NEUMARK-SZTAINER, D.; PAXTON, S. J. Five-year change in body satisfaction among adolescents. Journal of Psychosomatic Research, v. 61, n. 4, p. 521-527, 2006. 
ENDLER, N. S. et al. Controllability, coping, efficacy, and distress. European Journal of Personality, v. 14, n. 3, 245-264, 2000.

FARIAS F. R.; CARVALHO, S. A. C. I. Escala de autoavaliação sobre o esquema corporal. Arquivos Brasileiros de Psicologia, v. 39, n. 3, p. 23-35, 1987.

FERNANDES, A. E. R. Avaliação da imagem corporal, hábitos de vida e alimentares em crianças e adolescentes de escolas públicas e particulares de Belo Horizonte. 2007. Dissertação de mestrado - Universidade Federal de Minas Gerais. Disponível em: http://www.medicina.ufmg.br/cpg/ped/ teses_dissert/2007_mestrado_ana_fernandes.pdf

FIELD, A. E. et al. Peer, parent and media influences on the development of weight concerns and frequent dieting among preadolescent and adolescent girls and boys. Pediatrics, v. 107, p. 54-60, 2001.

FOLKMAN, S.; LAZARUS, R. S. An analysis of coping in a middle-age community sample. Journal of Health and Social Behavior, v. 21, p. 219-239, 1980.

FOLKMAN, S.; LAZARUS, R. S. If it changes it must be a process: Study of emotion and coping during three stages of a college examination. Journal of Personality and Social Psychology, v. 48, p. 150-170, 1985.

FOLKMAN, S.; LAZARUS, R. S. Coping as a mediator of emotion. Journal of Personality and Social Psychology, v. 54, n. 3, p. 466-475, 1988.

FOLKMAN, S.; LAZARUS, R. S. Manual for the Ways of Coping Questionnaire. Palo Alto, CA: Consulting Psychologists Press, 1988.

FOLKMAN, S et al. Dynamics of a stressful encounter: Cognitive appraisal, coping, and encounter outcomes. Journal of Personality and Social Psychology, v. 50, n. 5, p. 9921003, 1986.

FOLKMAN, S., MOSKOWITZ, J. T. Coping: Pitfalls and promise. Annual Review of Psychology, v. 55, p. 745-74, 2004.

FORSYTHE, C. J.; COMPAS, B. E. Interaction of cognitive appraisals of stressful events and coping: Testing the goodness of fit hypothesis. Cognitive Therapy and Research, v. 11, n. 4, p. 473-485, 1987. 
FRYDENBERG, E.; LEWIS, R. Adolescent coping: The different ways in which boys and girls cope. Journal of Adolescence, v. 14, n. 2, p. 119-133, 1991.

FRYER, S.; WALLER, G.; KROESE, B. S. Stress, coping, and disturbed eating attitudes in teenage girls. International Journal of Eating Disorders, v. 22, n. 4, p. 427-436, 1997.

GARCIA, C. Conceptualization and measurement of coping during adolescence: A review of the literature. Journal of Nursing Scholarship, v. 42, n. 2, p. 166-185, 2010.

GARROW, J. S.; WEBSTER, J. Quetelet's index (W/H2) as a measure of fatness. International Journal of Obesisty, v. 9, n. 2, p. 147-153, 1985.

GAMBARDELlA, A. M. D.; FRUTUOSO, M. F. P.; FRANCHI, C. Prática alimentar de adolescentes. Revista de Nutrição, Campinas, v.12, n. 1, p. 55- 63, 1999.

GARCÍA-GRAU, E. et al. Coping style and disturbed eating attitudes in adolescent girls. The International Journal of Eating Disorders, v. 32, n. 1, p. 116-120, 2002.

GARDNER, R. M.; BROWN, D. L. Body image assessment: A review of figural drawing scales. Personality and Individual Differences, v. 48, p. 107-111, 2010.

GARDNER, R. M. et al. Development and validation of two new scales for assessment of body-image. Perceptual and Motor Skills, v. 89, p. 981-993, 1999.

GARDNER, R. M.; JAPPE, L. M.; GARDNER, L. Development and validation of a new figural drawing scale for body-image assessment: The BIAS-BD. Journal of Clinical Psychology, v. 65, p. 113-122, 2009.

GARFINKEL, P. E.; NEWMAN, A. The Eating Attitudes Test: Twenty-five years later. Eating and Weight Disorders, v. 6, p. 1-24, 2001.

GLEESON, K.; FRITH, H. (De) constructing body image. Journal of Health Psychology, v. 11, n. 1, p. 79-90, 2006.

GRABE, S.; WARD, L. M.; HYDE, J. S. The role of the media in body image concerns among women: A meta-analysis of experimental and correlational studies. Psychological Bulletin, v. 134, p. 460-476, 2008. 
GREENO, C. G.; WING, R. R. Stress-induced eating. Psychological Bulletin, v. 115, p. 444464, 1994.

GRIFFITH, M. A.; DUBOW, E. F.; IPPOLITO, M. F. Developmental and cross-situational differences in adolescents' coping strategies. Journal of Youth and Adolescence, v. 29, p. 183-204, 2000.

GROESZ, L. M.; LEVINE, M. P.; MURNEN, S. K. The effect of experimental presentation of thin media images on body satisfaction: A meta-analytic review. Journal of International Eating Disorders, v. 31, n. 1, p. 1-16, 2002.

GROGAN, S. Body image: Understanding body dissatisfaction in men, women and children. London: Routledge, 2008.

GUTMAN, L. M.; ECCLES, J. S. Stage-environment fit during adolescence: Trajectories of family relations and adolescent outcomes. Developmental Psychology, v. 43, n. 2, p. 522537, 2007.

HAMPEL, P.; PETERMANN, F. Age and gender effect on coping in children and adolescents. Journal of Youth and Adolescence, v. 34, n. 2, p.73-83, 2005.

HENDERSON, P. A.; KELBEY, T. J.; ENGEBRETSON, K. M. Effects of a stress control program on children's locus of control, self-concept and coping behavior. The School Counselor, v. 40, p. 125-130, 1992.

HINOJOSA-LABORDE, C. et al. Gender differences in sympathetic nervous system regulation. Clinical and Experimental Pharmacology and Physiology, v. 26, p. 122-126, 1999.

HARRISON, K. The body electric: Thin-ideal media and eating disorders in adolescents. Journal of Communication, v. 50, n. 3, p. 119-143, 2006.

HOLSEN, I.; KRAFT, P.; ROYSAMB, E. The relationship between body image and depressed mood in adolescence: A 5-year longitudinal panel study. Journal of Health Psychology, v. 6, p. 613-627, 2001.

HOMAN, K. Athletic-ideal and thin-ideal internalization as prospective predictors of body dissatisfaction, dieting, and compulsive exercise. Body Image, v. 7, n. 3, p. 240-245, 2010. 
INSTITUTO BRASILEIRO DE GEOGRAFIA E ESTATÍSTICA (IBGE). Pesquisa de Orçamentos Familiares (POF) 2002-2003: antropometria e análise do estado nutricional de crianças e adolescentes no Brasil. Rio de Janeiro: IBGE, 2006.

JAARSVELD, C. H. M. et al. Perceived stress and weight gain in adolescence: A longitudinal analysis. Obesity, v. 17, n. 12, 2009.

JEWETT, J. Reviews of research: Childhood stress. Childhood education, v. 73, n. 3, p. 172-173, 1997.

JOËLS, M.; BARAM, T. Z. The neuro-symphony of stress. Nature Reviews Neuroscience, v. 10, p. 459-466, 2009.

JOHNSON, F.; WARDLE, J. Dietary restraint, body dissatisfaction, and psychological distress: A prospective analysis. Journal of Abnormal Psychology, v. 114, p.119-125, 2005.

JONES, D. C.; VIGFUSDOTTIR, T. H.; LEE, Y. Body image and the appearance culture among adolescent girls and boys: An examination of friend conversations, peer criticism, appearance magazines, and the internalization of appearance ideals. Journal of Adolescent Research, v. 19, p. 323-339, 2004.

KAGAWA, M. et al. A comparison of body perceptions in relation to measured body composition in young Japanese males and females. Body Image, v. 4, n. 4, p. 372-380, 2007.

KAKESHITA, I. S.; ALMEIDA, S. S. Relação entre índice de massa corporal e a percepção da auto-imagem em universitários. Revista de Saúde Pública, v. 40, n. 3, 497-504, 2006.

KAKESHITA, I. S.; SILVA, A. I. P.; ZANATTA, D. P.; ALMEIDA, S. S. Construção e fidedignidade teste-reteste de escalas de silhuetas brasileiras para adultos e crianças. Psicologia: Teoria e Pesquisa, v. 25, n. 2, p. 263-270, 2009.

KASHUBECK-WEST, S.; MINTZ, L. B.; SAUNDERS, K. J. Assessment of eating disorders in women. The Counseling Psychologist, v. 29, n. 5, p. 662-694, 2001.

KIM, D. Body image dissatisfaction as an important contributor to suicidal ideation in Korean adolescents: Gender difference and mediation of parent and peer relationships. Journal of Psychosomatic Research, v. 66, p. 297-303, 2009. 
KNAUSS, C.; PAXTON, S. J.; ALSAKER, F. D. Relationship amongst body dissatisfaction, internalization of the media body ideal and perceived pressure from media in adolescent girls and boys. Body Image, v. 4, p. 353-360, 2007.

KOFF, E.; SANGANI, P. Effects of coping style and negative body image on eating disturbance. International Journal of Eating Disorders, v. 22, n. 1, p. 51-56, 1997.

KOSTANSKI, M.; FISCHER, A.; GUALLANE, E. Current conceptualization of body image dissatisfaction: Have we got it wrong. Journal of Child Psychology and Psychiatry, v. 45, n. 7, p. 1317-1325, 2004.

KRONENFELD, L. W. et al. Ethnic and racial differences in body size perception and satisfaction. Body Image, v. 7, n. 2, p. 131-136, 2010.

LAUS, M. F. Estudo das relações entre prática de atividade física, estado nutricional e percepção da imagem corporal em adolescentes do ensino médio de Ribeirão Preto - SP. 2009. 146 f. Dissertação - Faculdade de Filosofia, Ciências e Letras de Ribeirão Preto, Universidade de São Paulo, Ribeirão Preto, 2009.

LAZARUS, R. S.; FOLKMAN, S. Stress, appraisal and coping. New York: Springer, 1984.

LEMON, S. C. et al. Contributions of weight perceptions to weight loss attempts: Differences by body mass index and gender. Body Image, v. 6, p. 90-96, 2009.

LEVINE, M. P., SMOLAK, L. Body image development in adolescence. In: CASH, T. F.; PRUZINSKY, T. (Eds.). Body image: A handbook of theory, research, and clinical practice. New York, NY: Guilford Press, 2002.

LEVINE, M. P.; SMOLAK, L.; HAYDEN, H. The relation of sociocultural factors to eating attitudes and behaviors among middle school girls. Journal of Early Adolescence, v. 14, p. 471-490, 1994.

LEWIS, R.; FRYDENBERG, E. Concomitants of failure to cope: What we should teach adolescents about coping. British Journal of Educational Psychology, v. 72, p. 419-431, 2002.

LIN, L.; REID, K. The relationship between media exposure and antifat attitudes: The role of dysfunctional appearance beliefs. Body Image, v. 6, n. 1, p. 52-55, 2009. 
LIPP, M. E. N. Manual do inventário de sintomas de stress para adultos. São Paulo: Casa do Psicólogo, 2000.

LIPP, M. E. N. O modelo quadrifásico do stress. In: LIPP, M. E. N. Mecanismos neuropsicofisiológicos do stress: teorias e aplicações clínicas. São Paulo: Casa do Psicólogo, 2003. p. 17-22.

LUPIEN, S. J. et al. Effects of stress throughout the lifespan on the brain, behavior and cognition. Nature Reviews Neuroscience, v. 10, p. 434-445, 2009.

MADRIGAL-FRITSCH, H. et al. Percepción de la imagen corporal como aproximación cualitativa al estado de nutrición. Salud pública de México, v. 41, p. 479-486, 1999.

MARTINS, P. O.; TRINDADE, Z. A.; ALMEIDA, A. M. O. O ter e o ser: representações sociais da adolescência entre adolescentes de inserção urbana e rural. Psicologia: Reflexão e Crítica, v. 16, p. 555-568, 2003.

MAYHEW, R.; EDELMANN, R. J. Self-esteem, irrational beliefs and coping strategies in relation to eating problems in a non-clinical population. Personality and Individual Differences, v. 10, n. 5, p. 581-584, 1989.

McCABE, M. P.; RICCIARDELLI, L. A. A longitudinal study of pubertal timing and extreme body change behaviors among adolescent boys and girls. Adolescence, v. 39, p. 145166, 2004.

McCABE, M. P.; RICCIARDELLI, L. A.; BANFIELD, S. Body image, strategies to change muscles and weight, and puberty: Do they impact on positive and negative affect among adolescent boys and girls? Eating Behaviors, v. 2, n. 2, p. 129-149, 2001.

McCABE, M. P.; RICCIARDELLI, L. A.; SITARAM, G.; MIKHAIL, K. Accuracy of body size estimation: Role of biopsychosocial variables. Body Image, v. 3, p. 163-171, 2006.

McDONOUGH, P.; WALTERS, V. Gender and health: Reassessing patterns and explanations. Social Science \& Medicine, v. 52, n. 4, p. 547-559, 2001.

MELLOR, D. et al. Sociocultural influences on body dissatisfaction and body change behaviors among Malaysian adolescents. Body Image, v. 6, p. 121-128, 2009. 
MENDEZ, M. A.; MONTEIRO, C. A.; POPKIN, B. M. Overweight exceeds underweight among women in most developing countries. The American Journal of Clinical Nutrition, v. 81, p. 714-721, 2005.

MICHAUD, C. I. et al. Relationships between a critical life event and eating behaviour in high school students. Stress Medicine, v. 6, p. 57-64, 1990.

MILLER, S. M.; KIRSCH, N. Sex differences in cognitive coping with stress. In: BARNETT, R. C.; BIENER, L.; BARUCH, G. K. (Eds.). Gender \& Stress. New York: The Free Press, 1987.

MONTEATH, S. A.; McCABE, M. P. The influence of societal factors on female body image. The Journal of Social Psychology, v. 137, n. 6, p. 708-727, 1997.

MULYE, T. P. et al. Trends in adolescent and young adult health in the United States. Journal of Adolescent Health, v. 45, p. 8-24, 2009.

MURRAY, K. M.; BYRNE, E.; RIEGER, E. Investigating adolescent stress and body image. Journal of Adolescence, 2010.

MUTH, J. L.; CASH, T. F. Body-Image attitudes: What difference does gender make? Journal of Applied Social Psychology, v. 27, n. 16, p. 1438-1452, 1997.

NEIGHBORS, L. et al. Weighing weight: Trends in body weight evaluation among young adults, 1990 and 2005. Sex Roles, v. 59, p. 68-80, 2008.

NEUMARK-SZTAINER, D. et al. Factors influencing food choices of adolescents: findings from focus-group discussions with adolescents. Journal of the American Dietetic Association, v. 99, n. 8, p. 929-937, 1999.

NEUMARK-SZTAINER, D. et al. Obesity, disordered eating, and eating disorders in a longitudinal study of adolescents: How do dieters fare 5 years later? Journal of the American Dietetic Association, v. 106, n. 4, p. 559-568, 2006.

NEUTZLING, M. B. et al. Frequência de consumo de dietas ricas em gordura e pobres em fibra entre adolescentes. Revista de Saúde Pública, v. 41, n. 3, p. 336-342, 2007.

NEWCOMBE, N. Desenvolvimento infantil: Abordagem de Mussen. Porto Alegre: Artes Médicas Sul. 2009. p. 404. 
NGUYEN-RODRIGUEZ, S. et al. BMI as a moderator of perceived stress and emotional eating in adolescents. Eating Behaviors, v. 9, n. 2, p. 238-246, 2008.

NICHOLLS, A. R. et al. Coping and coping effectiveness in relation to a competitive sport event: Pubertal status, chronological age, and gender among adolescent athletes. Journal of Sport and Exercise Psychology, v. 31, n. 3, p. 299-317, 2009.

NIEDER, T.; SEIFFGE-KRENKE, I. Coping with stress in different phases of romantic development. Journal of Adolescence, v. 24, p. 297-311, 2001.

ORGANIZAÇÃO MUNDIAL DA SAÚDE. Problemas de la salud de la adolescencia. Informe de un comité de expertos de la O.M.S (Informe técnico n 308). Genebra: 1965.

PARHAM, E. S. Promoting body size acceptance in weight management counseling. Journal of the American Dietetic Association, v. 99, p. 920-925, 1999.

PEARLIN, L. I.; SCHOOLER, C. The structure of coping. Journal of Health and Social Behavior, v. 19, n. 1, p. 2-21, 1978.

PELEGRINI, A.; PETROSKI, E. L. Inatividade física e sua associação com estado nutricional, insatisfação com a imagem corporal e comportamentos sedentários em adolescentes de escolas públicas. Revista Paulista de Pediatria, v. 27, n. 4, p. 366-73, 2009.

PETERSEN, A. C. et al. A self-image questionnaire for young adolescents (SIQYA): Reliability and validity studies. Journal of Youth and Adolescence, v. 13, p. 93-111, 1984.

PETERSON, M.; ELLENBERG, D.; CROSSAN, S. Body-image perceptions: Reliability of a BMI-based silhouette matching test. American Journal of Health Behavior, v. 27, p. 355363, 2003.

PETERSON, M.; ORSEGA-SMITH, E.; THOLSTRUP, L. Validity of the body mass index silhouette matching test. American Journal of Health Behavior, v. 28, p. 437-443, 2004.

PETERSON, K. A.; PAULSON, S. E.; WILliAMS, K. K. Relations of eating disorder symptomatology with perceptions of pressures from mothers, peers, and media in adolescent boys and girls. Sex Roles, v. 57, p. 629-639, 2007.

PETRIE, T. A. et al. Sociocultural expectations of attractiveness for males. Sex Roles, v. 35, p. 581-602, 1996. 
PINHEIRO, A. P.; GIUGLIANI, E. R. J. Insatisfação corporal em adolescentes escolares no Brasil: prevalência e fatores associados. Revista de Saúde Pública, v. 40, n. 3, p. 489-496, 2006.

PIRES, E. A. G. et al. Hábitos de atividade física e o estresse em adolescentes de Florianópolis-SC, Brasil. Revista Brasileira de Ciência e Movimento, v. 12, n. 1, p. 51-56, 2004.

POLIVY, J.; HERMAN, P. Sociocultural idealization of thin female body shapes: An introduction to the special issue on body image and eating disorders. Journal of Social and Clinical Psychology, v. 23, n. 1, p. 1-6, 2004.

POPE, H. G. et al. Evolving ideals of male body image as seen through action toys. International Journal of Eating Disorders, v. 26, p. 65-72, 1999.

PTACEK, J. T.; SMITH, R. E.; ZANAS, J. Gender, appraisal, and coping: A longitudinal analysis. Journal of Personality, v. 60, n. 4, p. 747-770, 1992.

QUADROS, T. M. B. et al. Imagem corporal em universitários: associação com estado nutricional e sexo. Motriz, v.16, n. 1, p. 78-85, 2010.

RICCIARDELLI, L. A.; McCABE, M. Children's body image concerns and eating disturbance: A review of the literature. Clinical Psychology Review, v. 21, n. 3, p. 325-344, 2001.

RODGERS, R.; CHABROL, H. Parental attitudes, body image disturbance and disordered eating amongst adolescents and young adults: A review. European Eating Disorders Review, v. 17, p. 137-151, 2009.

ROEMICH, J. N.; WRIGHT, S. M.; EPSTEIN, L. H. Dietary restraint and stress-induced snacking in youth. Obesity Research, v.10, p. 1120-1126, 2002.

RYAN, N. M. Stress-coping strategies identified from school age children's perspective. Research in Nursing and Health, v. 12, n. 2, p. 111-122, 1989.

SABBAH, H. A. et al. Body weight dissatisfaction and communication with parents among adolescents in 24 countries: International cross-sectional survey. BMC Public Health, v. 9, n. 52, p. 1-10, 2009. 
SAMUELSON, G. Dietary habits and nutritional status in adolescents over Europe: An overview of current studies in the Nordic countries. European Journal of Clinical Nutrition, v. 54, p. 21-28, 2000.

SAVÓIA, M. G.; SANTANA, P.; MEJIAS, N. P. Adaptação do inventário de estratégias de coping de Folkman e Lazarus para o português. Revista Psicologia USP, v. 6, 1996.

SCAGLIUSI, F. B. et al. Concurrent and discriminate validity of the Stunkard's figure rating scale adapted into Portuguese. Appetite, v. 47, p. 77-82, 2006.

SCHILDER, P. A Imagem do Corpo: As energias construtivas da psique. São Paulo: Martins Fontes, 1980.

SCHOEN-FERREIRA, T. H.; AZNAR-FARIAS, M.; SILVARES, E. F. D. M. Adolescência através dos séculos. Psicologia: Teoria e Pesquisa, v. 26, p. 227-234, 2010.

SEIDL, E. M. F.; TRÓCCOLI, B. T.; ZANNON, C. Análise fatorial de uma medida de estratégias de enfrentamento. Psicologia: Teoria e Pesquisa, v. 17, n. 3, p. 225-234, 2001.

SEIFFGE-KRENKE, I. Causal links between stressful events, coping style, and adolescent symptomatology. Journal of Adolescence, v. 23, p. 617-630, 2000.

SEIFFGE-KRENKE, I. Coping with relationship stressors: The impact of different working models of attachment and links to adaptation. Journal of Youth and Adolescence, v. 35, p. 25-39, 2006.

SEIFFGE-KRENKE, I.; AUNOLA; K.; NURMI, J. Changes in stress perception and coping during adolescence: The role of situational and personal factors. Child Development, v. 80, n. 1, p. 259-279, 2009.

SEIFFGE-KRENKE, I. et al. Coping with school-related stress and family stress in healthy and clinically referred adolescents. European Psychologist, v. 6, p. 123-132, 2001.

SELYE, H. Stress: a tensão da vida. $2^{\mathrm{a}}$ ed. São Paulo: Ibrasa, 1965.

SLADE, P. D.; RUSSELL, G. F. Awareness of body dimensions in anorexia nervosa: Crosssectional and longitudinal studies. Psychological Medicine, v. 3, n. 2, p. 188-199, 1973. 
SMOLAK, L. Body image in children and adolescents: Where do we go from here? Body Image, v. 1, p. 15-28, 2004.

SMOLAK, L.; STEIN, J. A. The relationship of drive for muscularity to sociocultural factors, self-esteem, physical attributes gender role, and social comparison in middle school boys. Body Image, v. 3, p. 121-129, 2006.

STANDLEY, R.; SULLIVAN, V.; WARDLE, J. Self-perceived weight in adolescents: Overestimation or under-estimation? Body Image, v. 6, p. 56-59, 2009.

STEGLISH, A. Terceira idade, aposentadoria, autoimagem e autoestima. 1978. Dissertação (Mestrado em Educação) - Faculdade de Educação, Universidade Federal do Rio Grande do Sul, 1978.

STICE, E.; BEARMAN, S. Body image and eating disturbances prospectively predict increases in depressive symptoms in adolescent girls: A growth curve analysis. Developmental Psychology, v. 37, p. 597-607, 2001.

STUNKARD, A. J.; SORENSON, T.; SCHLUSINGER, F. Use of the danish adoption register for the study of obesity and thinness. In: KETY, S. S.; ROWLAND, L. P.; SIDMAN, S. W.; MATTHYSSE, S. W. The genetics of neurological and psychiatric disorders. New York: Raven, 1983, p. 115-120.

TAMRES, L. K.; JANICKI, D.; HELGESON, V. S. Sex differences in coping behavior: A meta-analytic review and an examination of relative coping. Personality and Social Psychology Review, v. 6, n. 1, p. 2-30, 2002.

TAYLOR, S. E. et al. Biobehavioral responses to stress in females: Tend-and-befriend, not fight-or-flight. Psychological Review, v. 107, n. 3, p. 411-429, 2000.

THOMPSON, J. K. The (mis) measurement of body image: Ten strategies to improve assessment for applied and research purposes. Body Image, v. 1, p. 7-14, 2004.

THOMPSON, J. K.; ALTABE, M.; JOHNSON, S.; STORMER, S. M. Factor analysis of multiple measures of body image disturbance: Are we all measuring the same construct? International Journal of Eating Disorders, v. 16, n. 3, p. 311-315, 1994.

THOMPSON, J. K.; GARDNER, R. M. Measuring perceptual body image among adolescents and adults. In: CASH, T. F.; PRUZINSKY, T. Body image: A handbook of theory, research, and clinical practice. New York: Guilford, 2002. p. 135-141. 
THOMPSON, M. A.; GRAY, J. J. Development and validation of a new body image assessment scale. Journal of Personality Assessment, v. 64, n. 2, p. 258-269, 1995.

THORNTON, A.; ORBUCH, T. L.; AXINN, W. G. Parent-child relationships during the transition to adulthood. Journal of Family Issues, v. 16, p. 538-564, 1995.

TIGGEMANN, M. Nonreporting of body mass index: A research note on the interpretation of missing data. The International Journal of Eating Disorders, v. 39, n. 4, p. 346-349, 2006.

TIGGEMAN, M; WILSON-BARRETT; E. Children's figure ratings: Relationship to selfesteem and negative stereotyping. International Journal of Eating Disorders, v. 23, n. 3, p. 83-88, 1998.

TRICHES, R. M.; GIUGLIANE, E. R. J. Insatisfação corporal em escolares de dois municípios da região Sul do Brasil. Revista de Nutrição, Campinas, v. 20, n. 2, p. 119-128, 2007.

ULRICH-LAI, Y. M.; HERMAN, J. P. Neural regulation of endocrine and autonomic stress responses. Nature Reviews Neuroscience, v. 10, p. 397-409, 2009.

VEIGA, G. V.; CUNHA, A. S.; SICHIERI, R. Trends in overweight among adolescents living in the poorest and richest regions of Brazil. American Journal of Public Health, v. 94, n. 9, p. 1544-1548, 2004.

VINER, R. M. et al. Body mass, weight control behaviours, weight perception and emotional well being in a multiethnic sample of early adolescents. International Journal of Obesity, $v$. 30, p. 1514-1521, 2006.

VITALIANO, P. P. et al. Appraised changeability of a stressor as a modifier of the relationship between coping and depression: A test of the hypothesis of fit. Journal of Personality and Social Psychology, v. 59, n. 3, p. 582-592, 1990.

WILLIAMS, K.; McGILLICUDDY-DE LISI, A. Coping strategies in adolescents. Journal of Applied Developmental Psychology, v. 20, n. 4, p. 537-549, 1999.

WILLIAMSON, D. A. et al. Body image assessment for obesity (BIA-O): Development of a new procedure. International Journal of Obesity, v. 24, p. 1326-1332, 2000. 
WISEMAN, C. V. et al. Cultural expectations of thinness in women: An update. International Journal of Eating Disorders, v. 11, n. 1, p. 85-89, 1992.

YANG, S.; KIM, J.; YOON, J. Disturbed eating attitudes and behaviors in South Korean boys and girls: A school-based cross-sectional study. Yonsei Medical Journal, v. 51, n. 3, p. 302$309,2010$.

ZAKIR, N. S. Mecanismos de coping. In: LIPP, M. E. N. (Ed.). Mecanismos neuropsicofisiológicos do stress: Teoria e aplicações clínicas. São Paulo: Casa do Psicólogo, 2003. 
ANEXOS 


\section{ANEXOS}

\section{ANEXO 1}

Ribeirão Preto, __ de ___ de

Prezados Pais ou Responsáveis,

Venho, por meio desta, expor a pesquisa que desenvolvo como projeto de doutorado na Universidade de São Paulo sob orientação do Prof. Dr. Sebastião de Sousa Almeida no programa de Pós-graduação da Psicobiologia do Departamento de Psicologia e Educação da FFCLRP-USP, e solicitar seu consentimento para participação do seu filho nesse estudo.

O título da pesquisa é "Estresse, estratégias de enfrentamento e a percepção da imagem corporal em adolescentes: relações com o estado nutricional”. Este estudo é composto de três instrumentos que tem como objetivo avaliar o estresse dos participantes. Além disso, investigar como eles percebem a própria imagem corporal e como eles enfrentam essa questão, visto que a preocupação com a imagem corporal nos dias atuais tem aumentado a insatisfação corporal. Além desses instrumentos, um questionário socioeconômico será aplicado para identificação geral dos participantes (idade, sexo, série escolar, grau de instrução do chefe de família e posse de itens tais como televisão, geladeira, automóvel, etc) e o peso e a altura serão medidos, para avaliação do estado nutricional.

O tempo de participação é de um dia, com duração aproximada de 45 minutos. As atividades da pesquisa serão desenvolvidas em uma sala da escola, no período de aula.

Os adolescentes terão total liberdade e direito de desistir da realização da tarefa caso sintam-se desconfortáveis ou prejudicados, não havendo qualquer ônus de sua parte. Em nenhum momento os adolescentes terão despesas financeiras com a participação na pesquisa.

É importante ressaltar que o interesse está no conjunto de dados de todos os adolescentes. Estes serão utilizados no trabalho de doutorado da pesquisadora Gisele Straatmann e em publicações em revistas especializadas e congressos da área, garantindo o sigilo da identidade dos participantes. Portanto, em nenhum momento os participantes vão ser identificados publicamente.

A qualquer momento V.Sa. poderá discutir comigo qualquer questão ou dúvida e retirar seu consentimento, caso sinta-se desconfortável com a participação de seu filho.

No aguardo de um parecer favorável permaneço à sua disposição para outros esclarecimentos que se fizerem necessários.

Atenciosamente, 
Endereço: Laboratório de Nutrição e Comportamento, Universidade de São Paulo. Avenida Bandeirantes, 3900, Bloco 5 da Faculdade de Filosofia, Ciências e Letras de Ribeirão Preto. Bairro Monte Alegre, CEP: 14040-901 - Ribeirao Preto, SP - Brasil

Programa de Pós-Graduação em Psicobiologia

Departamento de Psicologia e Educação da FFCLRP-USP

\title{
Estresse, estratégias de enfrentamento e a percepção da imagem corporal em adolescentes: relações com o estado nutricional
}

\author{
AUTORIZAÇÃO
}

$\mathrm{Eu}$, ,autorizo meu(minha) filho(a)

a participar da pesquisa "Estresse, estratégias de enfrentamento e a percepção da imagem corporal em adolescentes: relações com o estado nutricional”, sob a responsabilidade de Gisele Straatmann e Sebastião de Sousa Almeida, a ser conduzida nas dependências da escola.

Declaro que li a carta na página anterior e que estou de acordo com o que foi proposto.

Pai / Mãe ou Responsável 
ANEXO 2

UNIVERSIDADE DE SÃO PAULO

FACULDADE DE FILOSOFIA, CIÊNCIAS E LETRAS DE RIBEIRÃO PRETO

COMITÊ DE ÉTICA EM PESQUISA - CEP

Of.CEtP/FFCLRP-USP. 017/2008-3/4/2008

Senhor(a) Pesquisador(a):

Comunicamos a V. Sa. que o trabalho intitulado "Estresse, estratégias de enfrentamento e a percepção da imagem corporal em adolescentes: relações com o estado nutricional" foi analisado pelo Comitê de Ética em Pesquisa da FFCLRP-USP, em sua $69^{\mathrm{a}}$ Reunião Ordinária realizada em 2/4/2008, e enquadrado na categoria: APROVADO, de acordo com o Processo CEP-FFCLRP n 369/2007 - 2007.1.2413.59.9

Atenciosamente,

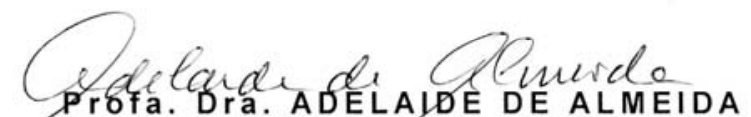

Coordenadora do Comitê de Ética em Pesquisa - FFCLRP-USP

Ilustrissimo(a) Senhor(a)

GISELE STRAATMANN

Aluna do Programa de Pós-Graduação em Psicobiologia

Desta FFCLRP-USP

c.c: Prof. Dr. SEBASTIÃO DE SOUSA ALMEIDA - Orientador

CEP-FFCLRP-USP - Fone: (016) 602-3653 - Fax: (016) 633-5015

Avenida Bandeirantes, 3900 - Bloco A - 14040-901 - Ribeirão Preto - SP - Brasil 
ANEXO 3

Questionário Socioeconômico

\section{ADOLESCENTE - IDENTIFICAÇÃO}

1. Nome:

2. Data de Nascimento:

3. Sexo: ( ) Masculino ( ) Feminino

4. Idade: anos

5. Série escolar:

\section{DADOS SOCIOECONÔMICOS}

1. Grau de Instrução do Chefe de Família (marque com um X)

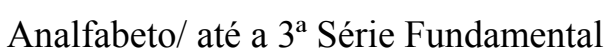

$4^{\mathrm{a}}$. Série Fundamental

Fundamental Completo

Médio Completo

Superior Completo

2. Posse de Itens (marque com um X)

\begin{tabular}{|c|c|c|c|c|c|}
\hline \multirow[t]{2}{*}{ Posse de itens } & \multirow[t]{2}{*}{ Não tem } & \multicolumn{4}{|c|}{ TEM (QUANTIDADE) } \\
\hline & & 1 & 2 & 3 & 4 \\
\hline Televisores em cores & & & & & \\
\hline Vídeocassete/ DVD & & & & & \\
\hline Rádios & & & & & \\
\hline Banheiros & & & & & \\
\hline Automóveis & & & & & \\
\hline Empregadas mensalistas & & & & & \\
\hline Máquinas de lavar & & & & & \\
\hline Geladeira & & & & & \\
\hline Freezer & & & & & \\
\hline
\end{tabular}




\section{ANEXO 4}

Inventário de Sintomas de Stress (ISSL LIPP, 2000)

\section{Quadro 1a}

Marque com um F1 os sintomas que tem experimentado nas últimas 24 horas.

1. Mãos e pés frios

2. Boca seca

3. Nó no estômago

4. Aumento de sudorese

5. Tensão muscular

6. Aperto da mandíbula / Ranger dos dentes

7. Diarréia passageira

8. Insônia

9. Taquicardia

10. Hiperventilação

11. Hipertensão arterial súbita e passageira

12. Mudança de apetite

\section{Quadro 1b}

Marque com um P1 os sintomas que tem experimentado nas últimas 24 horas.

13. Aumento súbito de motivação

14. Entusiasmo súbito

15. Vontade súbita de iniciar novos projetos

\section{Quadro 2a}

Marque com um F2 os sintomas que tem experimentado na última semana.

1. Problemas com a memória

2. Mal-estar generalizado, sem causa específica

3. Formigamento das extremidades

4. Sensação de desgaste físico constante

5. Mudança de apetite

6. Aparecimento de problemas dermatológicos

7. Hipertensão arterial

8. Cansaço constante

9. Aparecimento de úlcera

10. Tontura / Sensação de estar flutuando 


\section{Quadro 2b}

Marque com um P2 os sintomas que tem experimentado na última semana.

11. Sensibilidade emotiva excessiva

12. Dúvida quanto a si próprio

13. Pensar constantemente em um só assunto

14. Irritabilidade excessiva

15. Diminuição da libido

\section{Quadro 3a}

Marque com um F3 os sintomas que tem experimentado no último mês.

1. Diarréia freqüente

2. Dificuldades sexuais

3. Insônia

4. Náusea

5. Tiques

6. Hipertensão arterial continuada

7. Problemas dermatológicos prolongados

8. Mudança extrema de apetite

9. Excesso de gases

10. Tontura freqüente

11. Úlcera

12. Enfarte

\section{Quadro 3b}

Marque com um P3 os sintomas que tem experimentado no último mês.

13. Impossibilidade de trabalhar

14. Pesadelos

15. Sensação de incompetência em todas as áreas

16. Vontade de fugir de tudo

17. Apatia, depressão ou raiva prolongada

18. Cansaço excessivo

19. Pensar / Falar constantemente em um só assunto

20. Irritabilidade sem causa aparente

21. Angústia / Ansiedade diária

22. Hipersensibilidade emotiva

23. Perda do senso de humor 


\begin{abstract}
ANEXO 5
Inventário de Estratégias de Coping

Ways of Coping Inventory (Folkman e Lazarus, 1985) - adaptado por Savoia et al. (1996)
\end{abstract}

A "Imagem Corporal" é a figura mental que temos das medidas, dos contornos e da forma do nosso corpo, envolvendo como nós pensamos e sentimos sobre nossa própria aparência física.

Algumas situações e eventos que ocorrem ao longo da nossa vida podem influenciar negativamente nossa imagem corporal, ameaçando a habilidade de nos sentirmos bem a respeito de nossa aparência. Para lidar com essas situações, as pessoas utilizam diferentes estratégias.

Abaixo há uma lista englobando pensamentos e ações que as pessoas utilizam para lidar com essas situações. Pense em uma situação particular que aconteceu com você envolvendo sua aparência física e a descreva brevemente. Em cada item do questionário, pense sobre como você enfrentou, lidou com esse evento ou situação que abalou seus sentimentos a respeito de sua imagem corporal. Utilize a escala abaixo ( 0 a 3$)$ para indicar o quanto você usou cada um dos itens na situação descrita por você.

Não há respostas certas ou erradas. Não responda baseado em como você gostaria de ter reagido e sim como você agiu nessa situação.

Leia cada item abaixo e indique, fazendo um círculo na categoria apropriada, o que você fez na situação

de acordo com a seguinte classificação:

0 . não usei esta estratégia

1. usei um pouco

2. usei bastante

3. usei em grande quantidade

1. Concentrei-me no que deveria ser feito em seguida, no próximo passo

2. Tentei analisar o problema para entendê-lo melhor

3. Procurei trabalhar ou fazer alguma atividade para me distrair

4. Deixei o tempo passar - a melhor coisa que poderia fazer era esperar. O tempo é o $\quad \begin{array}{llllll}0 & 1 & 2 & 3\end{array}$ melhor remédio 
5. Procurei tirar alguma vantagem da situação $\quad 0 \quad 123$

6. Fiz alguma coisa que acreditava não dar resultados, mas ao menos estava fazendo $\quad 0 \quad \begin{array}{llllll}0 & 1 & 2\end{array}$ alguma coisa

7. Tentei encontrar a pessoa responsável para mudar suas idéias $\quad 0 \quad 123$

8. Conversei com outra (s) pessoa (s) sobre o problema, procurando mais dados sobre $\quad 0 \quad 1 \quad 2 \quad 3$ a situação

9. Critiquei-me, repreendi-me $\quad 0 \quad 123$

10. Tentei não fazer nada que fosse irreversível, procurando deixar outras opções $\quad \begin{array}{llll}0 & 1 & 2 & 3\end{array}$

11. Esperei que um milagre acontecesse $\quad 0 \quad 123$

12. Concordei com o fato, aceitei o meu destino $\quad 0 \quad 123$

13. Fiz como se nada tivesse acontecido $\quad 0 \quad 123$

14. Procurei guardar para mim mesmo (a) os meus sentimentos $\quad 0 \quad 123$

15. Procurei encontrar o lado bom da situação $\quad 0 \quad 123$

16. Dormi mais que o normal $\quad \begin{array}{llll}0 & 1 & 2\end{array}$

17. Mostrei a raiva para as pessoas que causaram o problema $\quad \begin{array}{llll}0 & 1 & 2\end{array}$

18. Aceitei a simpatia e a compreensão das pessoas $\quad \begin{array}{llll}0 & 1 & 2\end{array}$

19. Disse coisas a mim mesmo (a) que me ajudassem a me sentir bem $\quad \begin{array}{llll}0 & 1 & 3\end{array}$

20. Inspirou-me a fazer algo criativo $\quad 0 \quad 123$

21. Procurei a situação desagradável $\quad 0 \quad 123$

22. Procurei ajuda profissional $\begin{array}{llll}0 & 1 & 3\end{array}$

23. Mudei ou cresci como pessoa de uma maneira positiva $\quad 0 \quad 123$

24. Esperei para ver o que acontecia antes de fazer alguma coisa $\quad 0 \quad 123$

25. Desculpei ou fiz alguma coisa para repor os danos $\quad 0 \quad 123$

26. Fiz um plano de ação e o segui $\quad 0 \quad 123$

27. Tirei o melhor da situação, o que não era esperado $\quad 0 \quad 123$

28. De alguma forma extravasei os meus sentimentos $\quad 0 \quad 123$

29. Compreendi que o problema foi provocado por mim $\quad 0 \quad 123$

30. Saí da experiência melhor do que eu esperava $\quad 0 \quad 123$

31. Falei com alguém que poderia fazer alguma coisa concreta sobre o problema $\quad \begin{array}{lllll}0 & 2 & 3\end{array}$

32. Tentei descansar, tirar férias a fim de esquecer o problema $\quad 0 \quad 123$

33. Procurei me sentir melhor, comendo, fumando, utilizando drogas ou medicação $\quad \begin{array}{lllll}0 & 1 & 2 & 3\end{array}$

34. Enfrentei como um grande desafio, fiz algo muito arriscado $\quad \begin{array}{llll}0 & 1 & 2\end{array}$

35. Procurei não fazer nada apressadamente ou seguir o meu primeiro impulso $\quad \begin{array}{lllll}0 & 1 & 2\end{array}$

36. Encontrei novas crenças $\quad 0 \quad 123$ 
37. Mantive meu orgulho não demonstrando os meus sentimentos

38. Redescobri o que é importante na vida

39. Modifiquei aspectos da situação para que tudo desse certo no final

40. Procurei fugir das pessoas em geral

41. Não me deixei impressionar, recusava-me a pensar muito sobre esta situação

$\begin{array}{llll}0 & 1 & 2 & 3\end{array}$

42. Procurei um amigo ou parente para pedir conselhos

$\begin{array}{llll}0 & 1 & 2 & 3\end{array}$

43. Não deixei que os outros soubessem da verdadeira situação

$\begin{array}{llll}0 & 1 & 2 & 3\end{array}$

44. Minimizei a situação me recusando a preocupar-me seriamente com ela

$\begin{array}{llll}0 & 1 & 2 & 3\end{array}$

45. Falei com alguém sobre como estava me sentindo

$\begin{array}{llll}0 & 1 & 2 & 3\end{array}$

46. Recusei recuar e batalhei pelo que eu queria

$\begin{array}{llll}0 & 1 & 2 & 3\end{array}$

47. Descontei minha raiva em outra (s) pessoa (s)

$\begin{array}{llll}0 & 1 & 2 & 3\end{array}$

48. Busquei nas experiências passadas uma situação similar

$\begin{array}{llll}0 & 1 & 2 & 3\end{array}$

49. Eu sabia o que deveria ser feito, portanto dobrei meus esforços para fazer o que $\quad \begin{array}{llllll}0 & 1 & 2 & 3\end{array}$ fosse necessário

50. Recusei a acreditar que aquilo estava acontecendo

51. Prometi a mim mesmo que as coisas serão diferentes da próxima vez

52. Encontrei algumas soluções diferentes para o problema

53. Aceitei, nada poderia ser feito

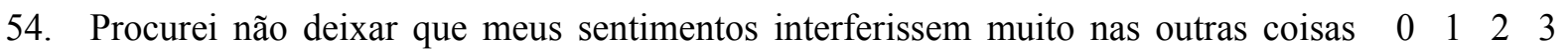
que eu estava fazendo

55. Gostaria de poder mudar o que tinha acontecido, ou como me senti

56. Mudei alguma coisa em mim, modifiquei-me de alguma forma

57. Sonhava acordado (a) ou imaginava um lugar ou tempo melhores do que aqueles $\quad 0 \begin{array}{lllll}0 & 1 & 2 & 3\end{array}$ em que eu estava

58. Desejei que a situação acabasse ou que de alguma forma desaparecesse

59. Tinha fantasias de como as coisas iriam acontecer, como se encaminhariam

60. Rezei

$\begin{array}{llll}0 & 1 & 2 & 3\end{array}$

61. Preparei-me para o pior

$\begin{array}{llll}0 & 1 & 2 & 3\end{array}$

62. Analisei mentalmente o que fazer e o que dizer

$\begin{array}{llll}0 & 1 & 2 & 3\end{array}$

63. Pensei em uma pessoa que admiro e a tomei como modelo

$\begin{array}{llll}0 & 1 & 2 & 3\end{array}$

64. Procurei ver as coisas sob o ponto de vista de outra pessoa

$\begin{array}{llll}0 & 1 & 2 & 3\end{array}$

65. Eu disse a mim mesmo (a) que as coisas poderiam ter sido piores

$\begin{array}{llll}0 & 1 & 2 & 3\end{array}$

66. Corri ou fiz exercícios 